\title{
Characterization of Ternary NiTiPd High-Temperature Shape-Memory Alloys under Load-Biased Thermal Cycling
}

\author{
GLEN S. BIGELOW, SANTO A. PADULA II, ANITA GARG, DARRELL GAYDOSH, \\ and RONALD D. NOEBE
}

\begin{abstract}
While NiTiPd alloys have been extensively studied for proposed use in high-temperature shapememory applications, little is known about the shape-memory response of these materials under stress. Consequently, the isobaric thermal cyclic responses of five $(\mathrm{Ni}, \mathrm{Pd})_{49.5} \mathrm{Ti}_{50.5}$ alloys with constant stoichiometry and Pd contents ranging from 15 to 46 at. pct were investigated. From these tests, transformation temperatures, transformation strain (which is proportional to work output), and unrecovered strain per cycle (a measure of dimensional instability) were determined as a function of stress for each alloy. It was found that increasing the Pd content over this range resulted in a linear increase in transformation temperature, as expected. At a given stress level, work output decreased while the amount of unrecovered strain produced during each load-biased thermal cycle increased with increasing Pd content, during the initial thermal cycles. However, continued thermal cycling at constant stress resulted in a saturation of the work output and nearly eliminated further unrecovered strain under certain conditions, resulting in stable behavior amenable to many actuator applications.
\end{abstract}

DOI: $10.1007 / \mathrm{s} 11661-010-0365-5$

(C) The Minerals, Metals \& Materials Society and ASM International 2010

\section{INTRODUCTION}

HigH-TEMPERATURE shape-memory alloys (HTSMAs) have received increased attention as the demand for lightweight, compact, and efficient actuators has grown in recent years. Of the known NiTi-based HTSMAs (alloys containing one or more of the alloying elements $\mathrm{Au}, \mathrm{Pd}, \mathrm{Pt}, \mathrm{Hf}$, or $\mathrm{Zr}$ ), NiTiPd has been one of the most extensively studied ${ }^{[1]}$ and is considered a prime candidate for use as a solid-state actuator in the aerospace, automotive, and energy exploration industries, where space is generally limited, the environment can be harsh, and alloys with a high transformation temperature are a necessity. ${ }^{[2]}$

Originally investigated in 1980 by Boriskina and Kenina, (Ni,Pd)Ti was identified as a stoichiometric pseudobinary system between NiTi and TiPd. ${ }^{[3]}$ In the ternary $(\mathrm{Ni}, \mathrm{Pd}) \mathrm{Ti}$ system, the high $\left(>773 \mathrm{~K}\left(500{ }^{\circ} \mathrm{C}\right)\right)$ transformation temperature of $\mathrm{TiPd}^{[4]}$ was shown to decrease linearly with decreasing $\mathrm{Pd}$ content to a minimum value near 10 at. pct $\mathrm{Pd}^{[5]}$ Later, Shimizu et al. determined that, as in binary $\mathrm{NiTi}$, transformation temperatures in NiTiPd were also extremely sensitive to the $(\mathrm{Ni}, \mathrm{Pd}): \mathrm{Ti}$ ratio on the Ti-lean side of stoichiometry, while alloys with Ti-rich compositions

GLEN S. BIGELOW, Materials Engineer, SANTO A. PADULA II and RONALD D. NOEBE, Materials Research Engineers, are with the NASA Glenn Research Center, Cleveland, $\mathrm{OH}$ 44135. Contact e-mail: glen.s.bigelow@nasa.gov ANITA GARG, Senior Research Associate, is with the University of Toledo, Toledo, OH 43606. DARRELL GAYDOSH, Senior Research Associate, is with the Ohio Aerospace Institute, Cleveland, OH, 44142.

Manuscript submitted February 16, 2010.

Article published online July 22, 2010 had transformation temperatures similar to those of stoichiometric compounds. ${ }^{[6]}$

Despite good unconstrained shape recovery in NiTiPd of up to 6 pct for alloys near 30 at. pct Pd and high transformation temperatures, ${ }^{[5,7]}$ unconstrained shape recovery is poor for alloys with higher $\mathrm{Pd}$ contents, decreasing to 4 pct for $\mathrm{Ni}_{13} \mathrm{Ti}_{50} \mathrm{Pd}_{37}$ in tension and less than 0.5 pet for alloys with $\mathrm{Pd}$ contents above 40 at. pct. ${ }^{[8]}$ Several methods were proposed for improving the shape recovery of these alloys by strengthening the material against plastic deformation. These included alloying with boron, ${ }^{[9]}$ heat treatment resulting in the precipitation of $\mathrm{Ti}_{2} \mathrm{Ni}$ type phases, ${ }^{[6]}$ and thermomechanical processing, which consisted of either cold rolling and subsequent heat treatment ${ }^{[10]}$ or isothermal mechanical cycling. ${ }^{[11]}$

Despite all the work performed on the NiTiPd system, there has been limited research investigating the shapememory response of these alloys under an applied load, which would be much more relevant to their use as solid-state actuators than measuring stress-free recovery. The most notable exceptions are more recent studies by Cai et al. ${ }^{[12]}$ on $\mathrm{Ni}_{19.4} \mathrm{Ti}_{50.6} \mathrm{Pd}_{30}$, Noebe et al. ${ }^{[13]}$ on $\mathrm{Ni}_{19.5} \mathrm{Ti}_{50.5} \mathrm{Pd}_{30}$, and Kumar et al. ${ }^{[14]}$ on $\mathrm{Ni}_{10} \mathrm{Ti}_{50} \mathrm{Pd}_{40}$. These studies were predominantly limited to higher Pd containing alloys. Consequently, in this investigation, load-biased thermal cycling has been used to determine the behavior of a series of NiTiPd alloys of constant stoichiometry (50.5 at. pct $\mathrm{Ti}$ ) with $\mathrm{Pd}$ contents ranging from 15 to 46 at. pct. By testing these materials under actuator-type conditions, one can determine the range of compositions from which viable HTSMAs can be developed. Doing so will lead to an understanding of the advantages and limitations of such materials and establish guidance for their appropriate use while 
identifying regimes where the development of new alloys and processing schemes will be necessary.

\section{MATERIALS AND PROCEDURES}

\section{A. Material Processing and Characterization}

Five alloys with Ti-rich target compositions of $\mathrm{Ni}_{49.5-x} \mathrm{Ti}_{50.5} \mathrm{Pd}_{x}(x=15,20,25,30$, and 46 at. pct $)$ were vacuum induction melted in graphite crucibles under a protective argon atmosphere using high-purity elemental constituents (99.98 wt pct Ni, 99.995 wt pct $\mathrm{Pd}$, and $99.95 \mathrm{wt}$ pct Ti) and cast into a 25.4-mmdiameter by $102-\mathrm{mm}-1$ ong copper mold. The mold was equipped with a conical hot-top section to accommodate shrinkage within the casting during solidification. The resulting ingots were vacuum homogenized for 72 hours at $1323 \mathrm{~K}\left(1050{ }^{\circ} \mathrm{C}\right)$ and furnace cooled. After homogenization, the hot tops were removed, the ingots were sealed in mild steel cans, and they were extruded at $1173 \mathrm{~K}\left(900{ }^{\circ} \mathrm{C}\right)$ through an area reduction of $7: 1$.

Each extrusion was sectioned into 50.8-mm-long cylindrical blanks using a wire electrical discharge machine. Blanks were center drilled on each end and rough turned on a computer numerically controlled (CNC) lathe. Final machining of the samples on the CNC lathe produced cylindrical dog-bone-shaped tensile samples with $3.81-\mathrm{mm}$ diameter by $16.4-\mathrm{mm}-\mathrm{long}$ gage sections and threaded button ends. To relieve any residual stresses from the machining operation, all of the samples were annealed at $673 \mathrm{~K}\left(400^{\circ} \mathrm{C}\right)$ for 1 hour and furnace cooled.

All the alloys were characterized while in this stressrelieved condition, including thermomechanical testing, density determination, compositional analysis, and microstructural characterization. Density was determined using Archimedes' Principle. Chemical compositions were quantitatively measured using several techniques depending on the element. Metallic elements were measured using inductively coupled plasma emission spectroscopy, while LECO* N/O and C/S determi-

*LECO is a trademark of LECO Corporation, St. Joseph, MI.

nators were used to measure nitrogen, oxygen, and carbon contents. Each alloy was mounted, polished, and imaged in a JEOL** 840 scanning electron microscope

**JEOL is a trademark of Japan Electron Optics Ltd., Tokyo.

(SEM) and Hitachi $^{\dagger} 4700$ field emission-scanning

\footnotetext{
${ }^{\dagger}$ Hitachi is a trademark of Hitachi High-Technologies Corporation, Tokyo, Japan.
}

electron microscope (FE-SEM) to determine the basic microstructure and the relative volume fractions and compositions of any minority phases and particles. Each alloy was also etched and imaged optically to reveal grain structure and size. All phases in the $\mathrm{Ni}_{19.5} \mathrm{Pd}_{30} \mathrm{Ti}_{50.5}$ alloy were positively identified by transmission electron microscopy (TEM) using a combination of electron diffraction and EDS analysis. This information was then used to identify and quantify the phases present in the remaining four alloys.

\section{B. Mechanical Testing}

All mechanical testing was performed on an MTS 810 servohydraulic load frame managed with an MTS FlexTest ${ }^{*}$ SE digital controller allowing operation and

${ }^{\ddagger}$ FlexTest is a trademark of MTS Systems Corporation, Eden Prairie, MN.

triggering of multiple control channels simultaneously. Samples were held by threaded inserts, which were screwed into hot grip extension rods held by watercooled hydraulic collet grips. Load was measured with a $100 \mathrm{kN} / 22 \mathrm{kip}$ load cell. Strain within the gage section was measured with a high-temperature water-cooled extensometer with a $12.7-\mathrm{mm}$ gage length and -10 / +20 pct strain range, which used alumina extension rods with v-chisel tips held in contact with the sample surface by a frictionless knife-edge holding fixture. A Eurotherm ${ }^{\S} 3504$ temperature controller with remote

${ }^{\S}$ Eurotherm is a trademark of Invensys Operations Management, Plano, TX.

set point was coupled with an Ameritherm NovaStar ${ }^{\S}$

${ }^{\S \S}$ NovaStar is a trademark of Ameritherm, Inc, Scottsville, NY.

$7.5 \mathrm{~kW}$ induction heater to heat the samples, while a muffin fan attached to one side of the load frame aided cooling. One type K thermocouple was spot welded to each threaded insert and monitored temperature at the sample extents. The temperature at the middle of the gage section was measured by a type $\mathrm{K}$ thermocouple spot-welded in series to a thin 0.127 -mm-diameter type $\mathrm{K}$ thermocouple wire. This thin wire was then spotwelded directly to the sample surface using a very low power setting to minimize surface damage from the welding process.

Load-biased thermal cycles were conducted in tension by straining the sample at a rate of $1 \times 10^{-4} \mathrm{~s}^{-1}$ until the desired stress was reached. At each constant stress level, the sample was thermally cycled twice $(20 \mathrm{~K} / \mathrm{min}$ heating, $30 \mathrm{~K} / \mathrm{min}$ cooling) from room temperature through the transformation to $\sim 100 \mathrm{~K}$ above the $A_{f}$ temperature and back. Samples were stressed in successive steps to $0,99,197,295,393$, and $517 \mathrm{MPa}$, or until failure occurred. All properties were measured from the second thermal cycle at each stress level. Raw data from 
the load-biased thermal cycling tests were converted to true strain and temperature measurements and analyzed using NASA GRC-developed software. The true straintemperature data were fitted using linear regression in three sections: the martensite coefficient of thermal expansion (CTE) region, the transformation region (fitting to the region of maximum slope), and the austenite CTE region (Figure 1). Transformation temperatures for the heating $\left(A_{s}, A_{f}\right)$ and cooling $\left(M_{s}, M_{f}\right)$ portions of each cycle were calculated using the intersection of the fit lines. Absolute strains in the austenite and martensite were measured at the beginning and end of each cooling cycle, respectively. Recovered transformation strain was calculated as the relative strain between the austenite finish and austenite start intersections. Relative work output (work per volume $\left(\mathrm{J} / \mathrm{cm}^{3}\right)$ ) at each stress level was calculated by multiplying the transformation strain by the applied stress. The amount of unrecovered or "open loop" strain per cycle was measured as the strain difference between the beginning of the heating curve and the end of the cooling curve. It should be noted that this value is the amount of unrecovered strain per cycle under the given test conditions, without any preconceived notion as to specific transformation/deformation mechanism. It may be possible to recover a part of this strain by subjecting the sample to a change in test environment, such as continued thermal cycling but under a stress-free condition. All of these measured values are clearly defined in Figure 1.

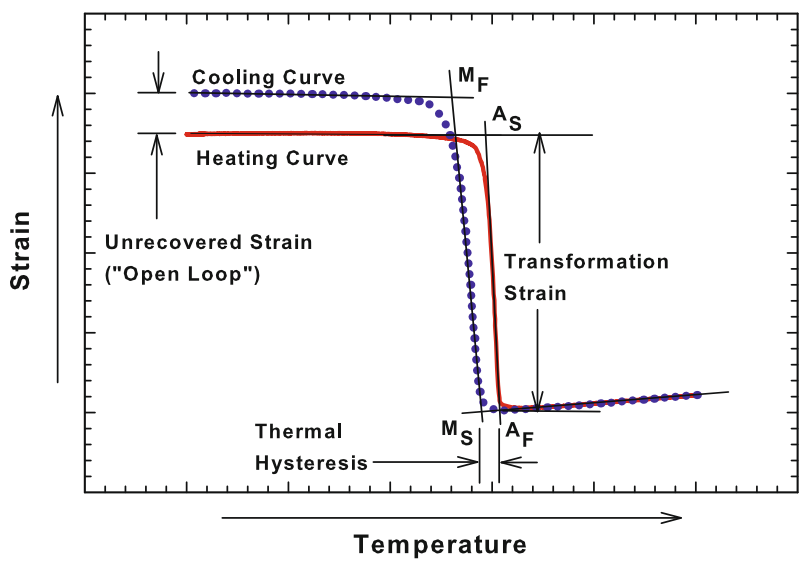

Fig. 1-Schematic illustration of a load-biased strain temperature cycle with measured values defined.

\section{RESULTS}

\section{A. Compositional and Microstructural Characterization}

The measured metallic compositions (Table I) were consistent with the original aim compositions, within the uncertainty of the analytical chemistry technique, which is approximately \pm 2 pct of the absolute value. Nickel was on target with a maximum measured deviation of \pm 0.08 at. pct, Pd deviated by a maximum of 0.2 at. pct above target, and $\mathrm{Ti}$ compositions averaged $49.6 \pm$ 0.3 at. pct. Quantitative chemical analysis revealed that the impurity contents of the alloys were $0.4 \pm 0.1$ at. pct $\mathrm{C}, 0.014 \pm 0.009$ at. pet $\mathrm{N}$, and $0.25 \pm 0.15$ at. pet $\mathrm{O}$, with the carbon contamination due to the use of graphite crucibles during melting.

Chemical analysis of the extruded and heat-treated alloys indicated that they were essentially stoichiometric in composition, with measured $\mathrm{Ti}:(\mathrm{Ni}+\mathrm{Pd})$ ratios ranging from 49.9:49.6 to 49.4:49.7. However, microstructural analysis indicated that all the alloys started out slightly $\mathrm{Ti}$ rich, based on the presence of a $\mathrm{Ti}_{2} \mathrm{Ni}$ type phase (Figure 2), consistent with their aim compositions.

Scanning electron microscopy (SEM) was performed on polished samples and revealed a predominantly single-phase martensitic matrix with a low-density distribution of two types of second-phase particles in all alloys. Representative SEM micrographs for all five alloys are shown in Figure 2. To identify the different phases, a detailed microstructural analysis was conducted on the $\mathrm{Ni}_{19.5} \mathrm{Ti}_{50.5} \mathrm{Pd}_{30}$ alloy using $\mathrm{SEM}, \mathrm{TEM}$, and X-ray diffraction (XRD) techniques. ${ }^{[13]}$ Full Reitveld analysis from XRD revealed the room-temperature crystal structure of the alloy to be B19 orthorhombic martensite with lattice parameters of $a=2.788 \AA$, $b=4.496 \AA$, and $c=4.760 \AA$. This was also confirmed by TEM analysis and agrees with the literature, which shows B19 to be the low-temperature phase for ternary NiTiPd alloys containing more than 10 at. pet $\operatorname{Pd}^{[3,15,16]}$

The second-phase particles (Figures 2 and 3) consisted of a Ti-rich phase containing predominantly carbon and an intermetallic phase containing $\mathrm{Ti}, \mathrm{Ni}$, and Pd. These phases appear in the SEM micrographs as a black phase and a gray phase, respectively (Figure 2(c), inset). Selected area diffraction (SAD) and electron dispersive spectroscopy (EDS) analysis of the former phase indicated that it was an fcc-structured TiC (Figure 3), while the intermetallic phase was a $\mathrm{Ti}_{2}(\mathrm{Ni}, \mathrm{Pd})$ phase (Figure 3) isostructural with the

Table I. Aim and Measured Composition (Atomic Percent) and Density for the Ternary NiTiPd Alloys

\begin{tabular}{|c|c|c|c|c|c|c|c|c|c|c|c|}
\hline \multirow[b]{2}{*}{ Sample ID } & \multicolumn{3}{|c|}{ Aim Composition } & \multicolumn{6}{|c|}{ Measured Composition } & \multirow[b]{2}{*}{ Ti:(Ni,Pd) Ratio } & \multirow[b]{2}{*}{ Density $\mathrm{g} / \mathrm{cm}^{3}$} \\
\hline & $\mathrm{Ti}$ & $\mathrm{Ni}$ & $\mathrm{Pd}$ & Ti & $\mathrm{Ni}$ & $\mathrm{Pd}$ & $\mathrm{C}$ & $\mathrm{N}$ & $\mathrm{O}$ & & \\
\hline EXT36 & 50.5 & 34.5 & 15 & 49.7 & 34.5 & 15.2 & 0.4 & 0.011 & 0.2 & $49.7: 49.7$ & 6.974 \\
\hline EXT37 & 50.5 & 29.5 & 20 & 49.9 & 29.5 & 20.1 & 0.3 & 0.009 & 0.2 & $49.9: 49.6$ & 7.231 \\
\hline EXT38 & 50.5 & 24.5 & 25 & 49.6 & 24.4 & 25.2 & 0.06 & 0.011 & 0.16 & $49.6: 49.8$ & 7.406 \\
\hline EXT24 & 50.5 & 19.5 & 30 & 49.6 & 19.5 & 30.2 & 0.4 & 0.017 & 0.3 & $49.6: 49.7$ & 7.504 \\
\hline EXT50 & 50.5 & 3.5 & 46 & 49.4 & 3.5 & 46.2 & 0.5 & 0.023 & 0.4 & $49.4: 49.7$ & 8.087 \\
\hline
\end{tabular}



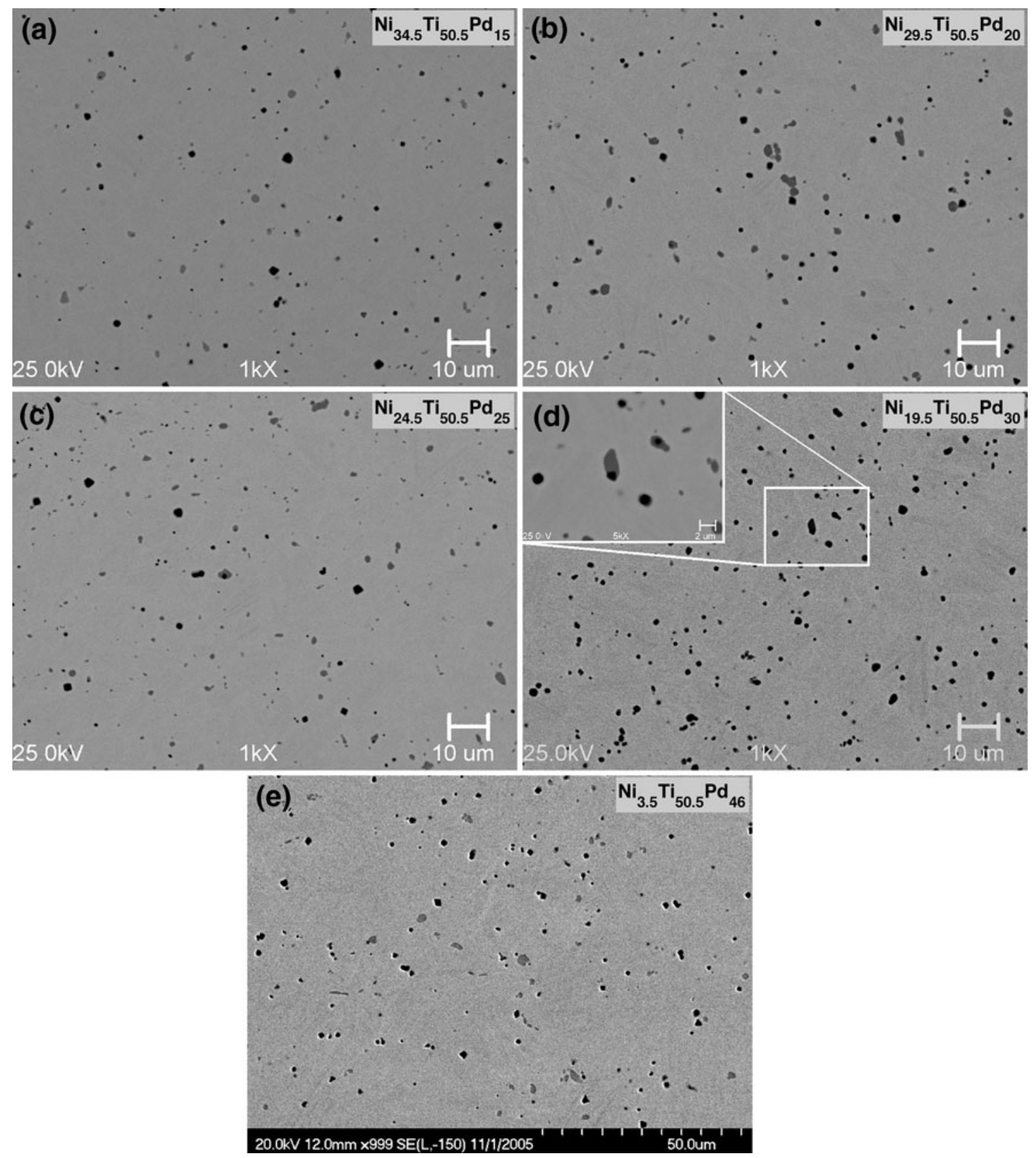

Fig. 2-Room-temperature backscattered electron images of the microstructure of the five alloys: $(a)$ through $(e)$ showing secondary phases in a B19 martensite matrix. The inset in (d) for $\mathrm{Ni}_{19.5} \mathrm{Ti}_{50.5} \mathrm{Pd}_{30}$ more clearly shows the two secondary phases: $\mathrm{TiC}-$ black, and $\mathrm{Ti}{ }_{4}(\mathrm{Ni}, \mathrm{Pd})_{2} \mathrm{O}_{x}-\mathrm{gray}$.

face-centered-cubic $\mathrm{Ti}_{2} \mathrm{Ni}$ phase found in binary Ti-rich NiTi alloys. ${ }^{[17]}$ It should be noted that the presence of $\mathrm{O}$ has been shown to stabilize a $\mathrm{Ti}_{4} \mathrm{Ni}_{2} \mathrm{O}_{x}$ phase in NiTi alloys. ${ }^{[18,19]}$ This phase has the same lattice parameter and crystal structure as the $\mathrm{Ti}_{2} \mathrm{Ni}$ phase since $\mathrm{O}$ resides interstitially in the $\mathrm{Ti}_{4} \mathrm{Ni}_{2} \mathrm{O}_{x}$ phase, which also makes it hard to detect. Thus, it is likely that the $\mathrm{Ti}_{2}(\mathrm{Ni}, \mathrm{Pd})$ phase in our alloys is also an O-stabilized $\mathrm{Ti}_{4}(\mathrm{Ni}, \mathrm{Pd})_{2} \mathrm{O}_{x}$ phase. The blocky morphology of this phase suggests that it formed interdendritically during solidification and then broke up during extrusion.

Analysis of the remaining four alloys (also shown in Figure 2) by SEM and EDS revealed that they too were composed at room temperature of a martensitic matrix interspersed with a small volume fraction of $\mathrm{TiC}$ and $\mathrm{Ti}_{2}(\mathrm{Ni}, \mathrm{Pd}) / \mathrm{Ti}_{4}(\mathrm{Ni}, \mathrm{Pd})_{2} \mathrm{O}_{x}$. In all five alloys, the average particle sizes of the two phases were $\sim 1.1$ and $1.5 \mu \mathrm{m}$ for the $\mathrm{TiC}$ and $\mathrm{Ti}_{2}(\mathrm{Ni}, \mathrm{Pd}) / \mathrm{Ti}_{4}(\mathrm{Ni}, \mathrm{Pd})_{2} \mathrm{O}_{x}$, respectively, with the total particle volume fraction less than 4 pct in any alloy.

Optical microscopy was performed on etched samples from all five alloys and revealed an equiaxed grain structure with an average grain size of 10 to $15 \mu \mathrm{m}$ in both the longitudinal and transverse directions. Figure 4 shows representative optical micrographs from all five alloys. The equiaxed grain structure is 


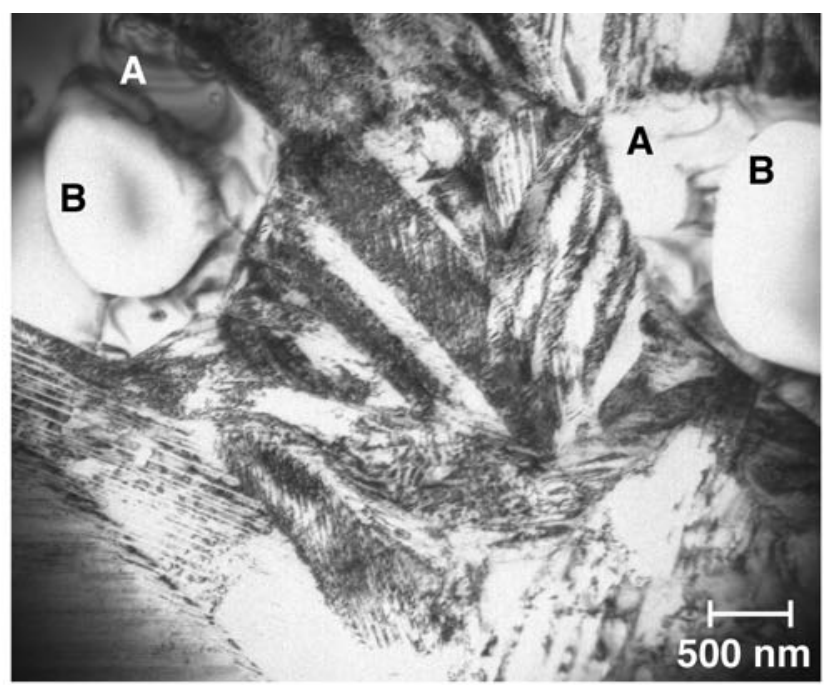

(a)

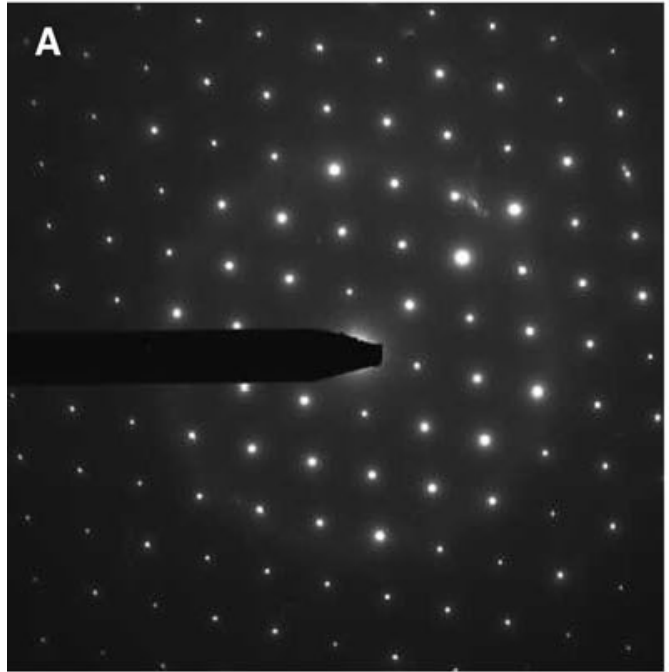

(b)

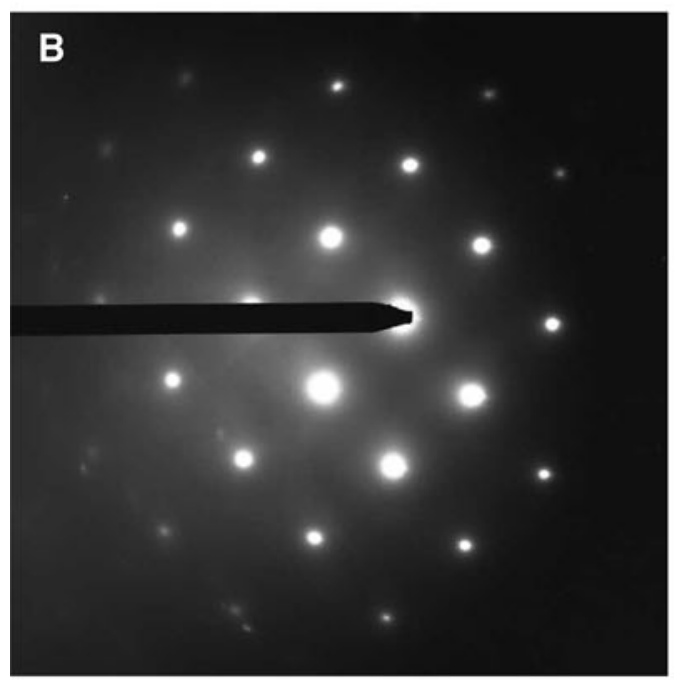

(d)

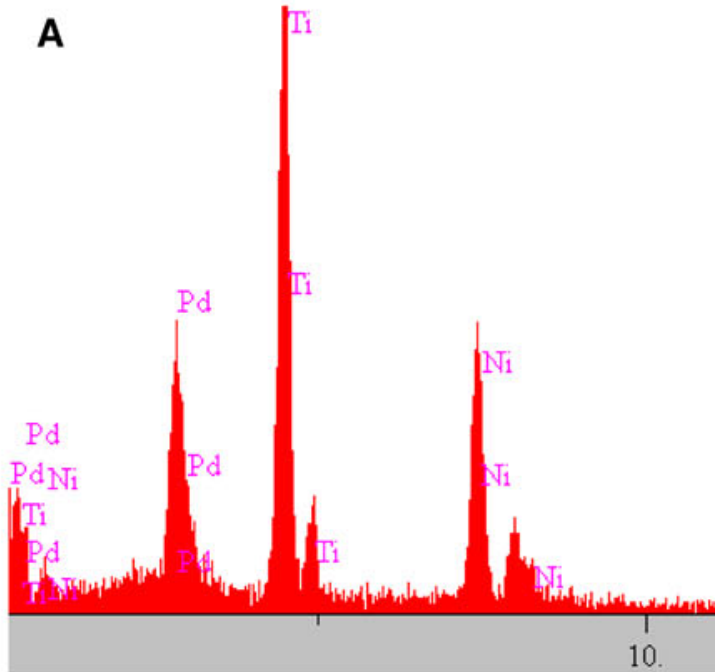

(c)

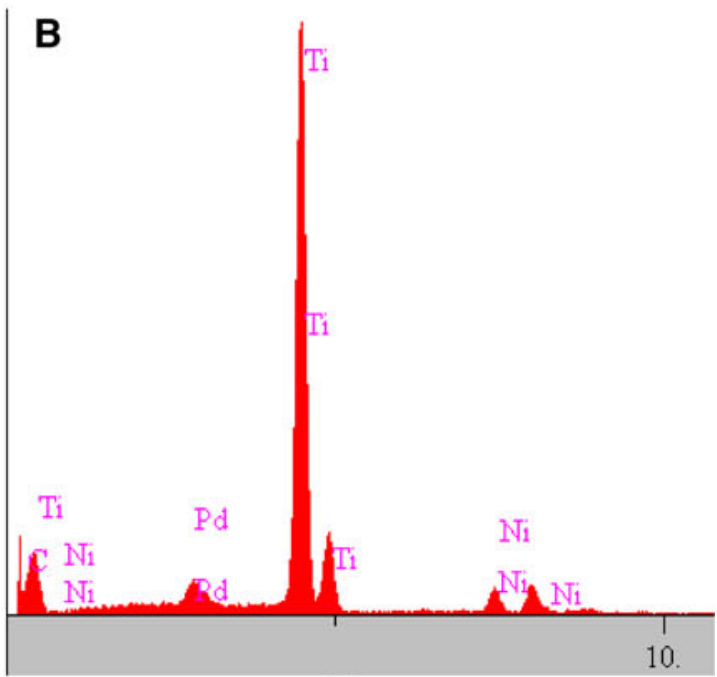

(e)

Fig. 3-TEM bright-field image of the microstructure of $\mathrm{Ni}_{19.5} \mathrm{Ti}_{50.5} \mathrm{Pd}_{30}$ showing the martensite matrix with two types of second-phase particles, $\mathrm{Ti}_{2}(\mathrm{Ni}, \mathrm{Pd})$ (labeled A) and TiC (labeled B), identified by their corresponding SADP and EDS spectra. 

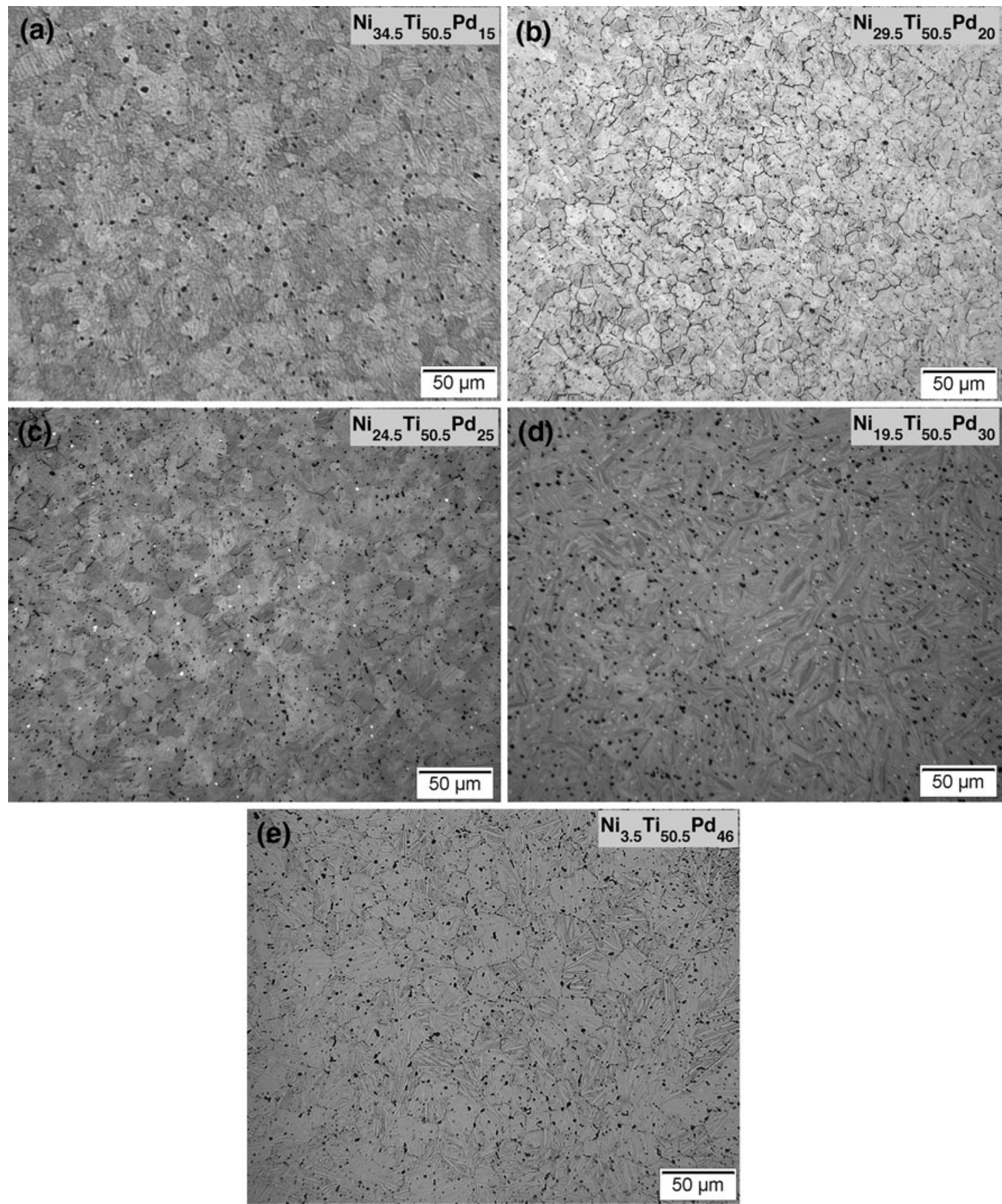

Fig. 4-Optical micrographs of all five alloys etched to reveal grain structure. Grains were equiaxed and measured an average of 10 to $15 \mu \mathrm{m}$ in both the longitudinal and transverse directions.

the result of dynamic recrystallization during the extrusion process.

Finally, density values for the five alloys are included in Table I. The density increased linearly with $\mathrm{Pd}$ content, from $6.97 \mathrm{~g} \mathrm{~cm}^{3}$ for the 15 at. pct Pd alloy to $8.09 \mathrm{~g} \mathrm{~cm}^{3}$ for the alloy with 46 at. pct Pd. The density of binary NiTi is $6.45 \mathrm{~g} \mathrm{~cm}^{3[20]}$ and increases in the ternary alloys with increasing replacement of $\mathrm{Ni}$ with the heavier Pd atom.

\section{B. Stress-Free Transformation Temperatures}

No-load transformation temperatures were determined via unconstrained thermal cycling, as described in Section II-B. The samples were thermally cycled under essentially zero load from $323 \mathrm{~K}\left(50{ }^{\circ} \mathrm{C}\right.$ ) (or room temperature in the case of the $\mathrm{Ni}_{34.5} \mathrm{Ti}_{50.5} \mathrm{Pd}_{15}$ alloy) to at least $100 \mathrm{~K}\left(100{ }^{\circ} \mathrm{C}\right)$ above the temperature where the transformation was observed to finish and then cooled 
to the starting temperature, while measuring strain (Figure 5). As the sample is heated, there is an increase in strain (volume) beyond that due to thermal expansion as the sample transforms from martensite to austenite and a corresponding decrease in strain during cooling through the transformation. The transformation temperatures determined from these curves, as well as the hysteresis values $\left(A_{f}-M_{s}\right)$, are shown in Table II. There is a linear increase in all transformation temperatures with increasing $\mathrm{Pd}$ content, as shown in Figure 6(a). From 15 to 30 at. pct $\mathrm{Pd}$, the change is $11.2,11.8,11.7$, and $11.7 \mathrm{~K} /$ at. pet $\mathrm{Pd}$, for the $M_{f}, M_{s}$, $A_{s}$, and $A_{f}$, respectively, so the transformation range $\left(A_{f}-M_{f}\right)$ and the hysteresis remain relatively constant for these compositions. However, somewhere between 30 and 46 at. pct $\mathrm{Pd}$, the slope changes, and if all the compositions are considered, the slopes become 13.1, $13.3,14.1$, and $13.9 \mathrm{~K} /$ at. pct $\mathrm{Pd}$ for the $M_{f}, M_{s}, A_{s}$, and $A_{f}$, respectively. Thus, with increasing $\mathrm{Pd}$ content, the $A_{s}$ and $A_{f}$ increase at a higher rate than the $M_{f}$ and $M_{s}$, leading to an increase in the hysteresis and the overall transformation range between the lower $\mathrm{Pd}$ content composition and the 46 at. pct Pd composition.

For comparison, the $M_{s}$ data for the NiTiPd alloys in this study are plotted in Figure 6(b) with similar data from a number of previous investigations. ${ }^{[3-5,21,22]}$ The data for the current alloys lie within the bounds of those

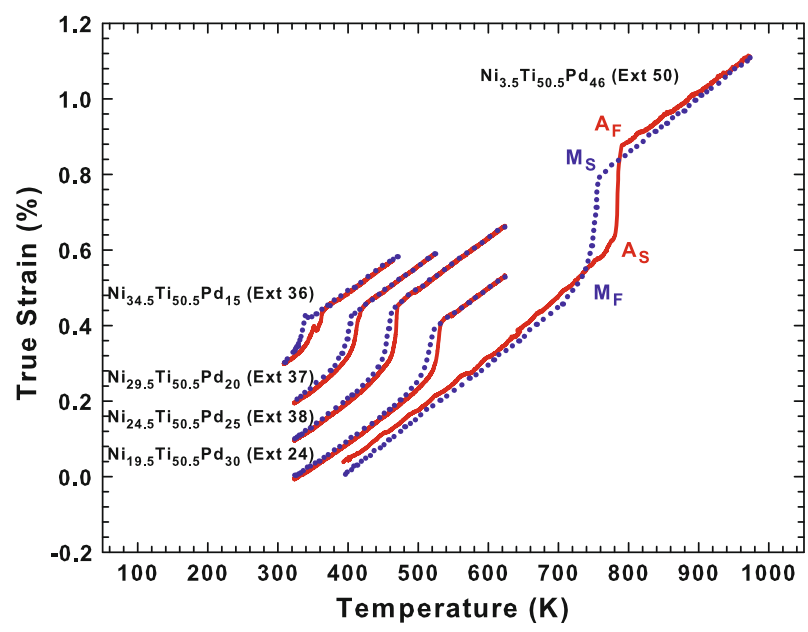

Fig. 5-No-load strain vs temperature response curves for all five alloys showing increasing transformation temperatures with increasing Pd content. values reported for stoichiometric $\mathrm{Ni}_{50-x} \mathrm{Pd}_{x} \mathrm{Ti}_{50}$ by Boriskina and Kenina ${ }^{[3]}$ and Lindquist and Wayman. ${ }^{[5]}$ This is expected, since, like binary NiTi, ${ }^{[23,24]} \mathrm{NiTiPd}$ transformation temperatures are extremely sensitive to $(\mathrm{Ni}, \mathrm{Pd})$ : Ti ratio on the $\mathrm{Ni}$-rich side of stoichiometry, but are much less sensitive between the Ti-rich and stoichiometric compositions. ${ }^{[6]}$ These data also reinforce the contention that the final compositions of the current alloys are very close to stoichiometry, if not slightly $\mathrm{Ti}$ rich.

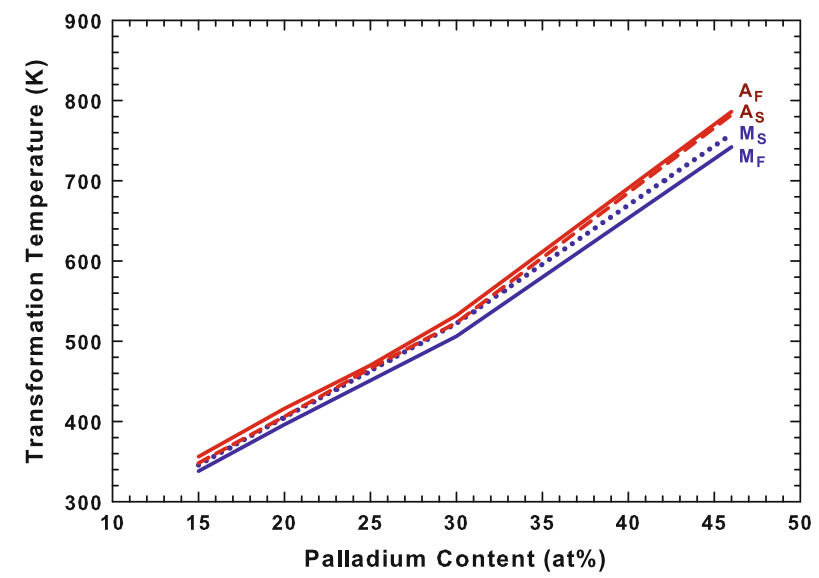

(a)

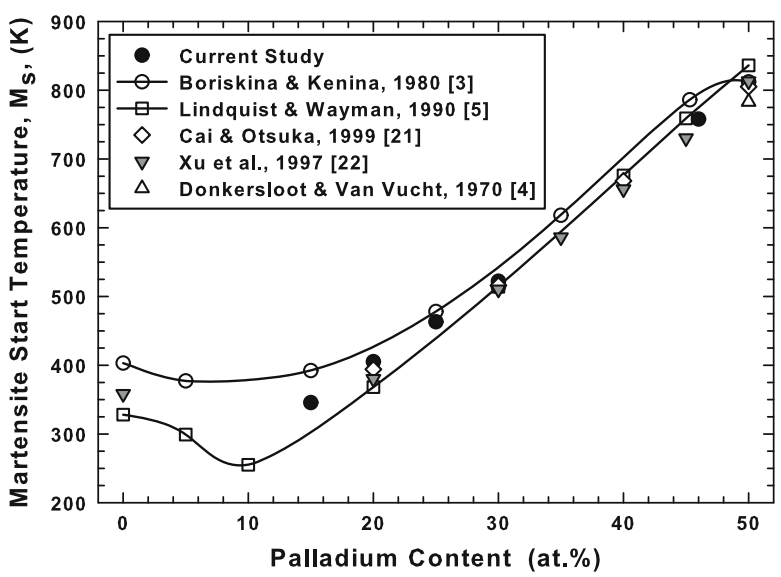

(b)

Fig. 6- (a) Nearly linear correlation between transformation temperatures and $\mathrm{Pd}$ content over the range of compositions investigated in this study. (b) Comparison of the $M_{s}$ temperatures for the alloys in this study with those of previous investigations. ${ }^{[3-5,21,22]}$

Table II. Unconstrained Transformation Temperatures and Thermal Hysteresis

\begin{tabular}{|c|c|c|c|c|c|c|c|c|c|c|}
\hline \multirow[b]{2}{*}{ Sample ID } & \multicolumn{3}{|c|}{$\begin{array}{l}\text { Aim Composition } \\
\text { (At. Pct) }\end{array}$} & \multicolumn{4}{|c|}{$\begin{array}{l}\text { Transformation } \\
\text { Temperature (K) }\end{array}$} & \multirow{2}{*}{$\begin{array}{c}\text { Thermal } \\
\text { Hysteresis } 1(\mathrm{~K}) \\
A_{f}-M_{s}(\text { standard })\end{array}$} & \multirow{2}{*}{$\begin{array}{c}\text { Thermal } \\
\text { Hysteresis } 2(\mathrm{~K}) \\
\left(A_{f}+A_{s}\right)-\left(M_{s}+M_{f}\right)\end{array}$} & \multirow{2}{*}{$\begin{array}{c}\text { Transformation } \\
\text { Strain (Pct) }\end{array}$} \\
\hline & $\mathrm{Ti}$ & $\mathrm{Ni}$ & $\mathrm{Pd}$ & $M_{f}$ & $M_{s}$ & $A_{s}$ & $A_{f}$ & & & \\
\hline EXT36 & 50.5 & 34.5 & 15 & 338 & 346 & 348 & 356 & 10 & 20 & -0.10 \\
\hline EXT37 & 50.5 & 29.5 & 20 & 396 & 405 & 406 & 416 & 11 & 21 & -0.14 \\
\hline EXT38 & 50.5 & 24.5 & 25 & 451 & 463 & 466 & 470 & 7 & 22 & -0.17 \\
\hline EXT24 & 50.5 & 19.5 & 30 & 506 & 522 & 523 & 532 & 10 & 27 & -0.21 \\
\hline EXT50 & 50.5 & 3.5 & 46 & 742 & 758 & 782 & 786 & 28 & 68 & -0.28 \\
\hline
\end{tabular}


For a fully-annealed, stress-free thermoelastic material, the volume change during transformation is due to a mismatch in lattice parameters between the selfaccommodated martensite and the austenite, and is usually small (less than $\sim 0.3 \mathrm{pct}$ ). ${ }^{[25]}$ For the current alloys, the transformation strain for a no-load thermal cycle increased linearly with respect to Pd content at $-7.4 \times 10^{-3} \mathrm{pct} / \mathrm{at}$. pct (for 15 to 30 at. pct $\mathrm{Pd}$ ) (Table II), indicating an increasing mismatch between the B2 and B19 lattice parameters with increasing Pd content. This would correlate with a linear increase in the middle eigen value, $\lambda_{2}$, of the transformation strain matrix for NiTiPd alloys with Pd contents above 10 at. pet. ${ }^{[26]}$ Thermal hysteresis is also related to $\lambda_{2}$, with minimum hysteresis at $\lambda_{2}=1(\sim 11$ at. pct Pd), increasing with deviation away from $\lambda_{2}=1$ (decreasing or increasing Pd content from 11 at. pct). ${ }^{[27]}$ When hysteresis is defined as $\left(A_{s}+A_{f}\right)-\left(M_{s}+M_{f}\right)$ as is done by Zhang et al. ${ }^{[27]}$ the current data show an increase in hysteresis, although not linear, from $20.5 \mathrm{~K}\left({ }^{\circ} \mathrm{C}\right)$ at 15 at. pct $\mathrm{Pd}$ to $68 \mathrm{~K}\left({ }^{\circ} \mathrm{C}\right)$ at 46 at. pct $\mathrm{Pd}$. However, in this work, the hysteresis, standardly defined as $A_{f}-M_{s}$, remains relatively constant at $\sim 10 \mathrm{~K}\left({ }^{\circ} \mathrm{C}\right)$ for a wide range in $\mathrm{Pd}$ contents (15 to 30 at. pct). This is significantly less than that typically observed for binary $\mathrm{NiTi}$, which generally exhibits a hysteresis of 30 to $50 \mathrm{~K}$ $\left({ }^{\circ} \mathrm{C}\right)$ for the B2 to monoclinic transformation, with Ti-rich compositions having the larger hystereses. ${ }^{[28]}$ This is consistent both with binary NiTi having a larger deviation from $\lambda_{2}=1$ than the NiTiPd alloys and with the relationship that the $\mathrm{B} 2-\mathrm{B} 19$ hysteresis is smaller than that for $\mathrm{B} 2-\mathrm{B} 19$ '. The $\mathrm{Ni}_{3.5} \mathrm{Ti}_{50.5} \mathrm{Pd}_{46}$ alloy exhibited a much larger hysteresis, approximately $28 \mathrm{~K}\left({ }^{\circ} \mathrm{C}\right)$, but still much smaller than the 80 to $100 \mathrm{~K}\left({ }^{\circ} \mathrm{C}\right)$ reported for the binary $\mathrm{Ti}_{50} \mathrm{Pd}_{50}$ composition. ${ }^{[8,12]}$

\section{Strain-Temperature Behavior under Constant Load}

Our primary interest in high-temperature shapememory alloys is in their potential to be used as highly loaded solid-state actuators and as major components in adaptive structures, particularly for aeronautic applications. Consequently, constant-load, strain-temperature tests were performed on each of the alloys as a method for evaluating the work output and dimensional stability under various constant loads. In this case, a single sample was used to determine the actuator-like characteristics of each alloy by loading it through a series of increasing stress levels $(0,99,197,295,393$, and $517 \mathrm{MPa}$ or until failure occurred), thermally cycling the alloy twice through the transformation regime at each stress. The validity of this technique compared to using individual samples at each stress level was previously demonstrated for a binary NiTi alloy. ${ }^{[29]}$

The reason for using the second complete thermal cycle for determining representative sample behavior is illustrated in Figure 7. This figure shows the straintemperature response of a $\mathrm{Ni}_{19.5} \mathrm{Ti}_{50.5} \mathrm{Pd}_{30}$ alloy under $99 \mathrm{MPa}$ stress for the first two complete thermal cycles. During the first thermal cycle at each load, the sample begins to "adjust" to the applied stress. Little strain is generated in the sample during the initial loading at

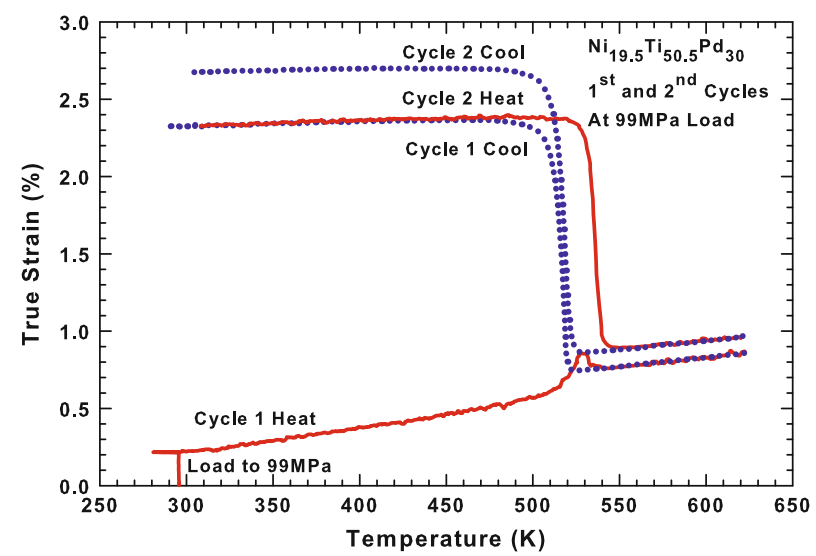

Fig. 7-Initial loading response and very first and second thermal cycles for $\mathrm{Ni}_{19.5} \mathrm{Ti}_{50.5} \mathrm{Pd}_{30}$ at $99 \mathrm{MPa}$.

room temperature, and therefore, relatively little strain is recovered on heating through the transformation. Upon cooling, the stress causes the austenite to transform to an oriented martensite with variants that tend to be optimally oriented to relieve the applied stress and maximize the strain, resulting in a large increase in strain upon cooling through the transformation. This larger strain is then recovered during subsequent heating. All succeeding cycles are then very similar to the second complete thermal cycle. Therefore, the second cycle at each applied stress level is used to determine the transformation strain, work output, and unrecovered strain for each alloy.

Figure 8 shows the second thermal cycle at each stress level for a standard load-biased thermal cycling test performed on each of the five NiTiPd alloys. Above each curve, the applied stress and resulting work output are shown. The recovered transformation strain, work output, and the open-loop or unrecovered component of strain during each complete thermal cycle were derived from these data for each alloy and are compiled in Figures 9,10 , and 11, respectively. The summary plots do not include data from the $\mathrm{Ni}_{3.5} \mathrm{Ti}_{50.5} \mathrm{Pd}_{46}$ alloy since the alloy produced no work output even at $99 \mathrm{MPa}$, but instead, when cycled through the transformation to the austenite state, simply elongated to failure during the initial heating cycle (Figure 8(e)).

In general, the recovered transformation strain increased with increasing stress, reaching a peak at $295 \mathrm{MPa}$ for all of the alloys (Figure 9). At stresses below this maximum, the transformation strain increased with stress, because the higher stresses were able to cause more of the martensite twin variants to reorient toward an orientation that favored the applied stress during cooling, therefore making more strain available to be recovered during the subsequent heating cycle during the transition to austenite. Eventually, at some level of stress, this reorientation effect is maximized, but further increases in stress become high enough to prevent full recovery of all the reoriented martensite, ${ }^{[30-32]}$ and so the transformation strain level peaks and begins to decrease. Work output, being the mathematical product of the transformation strain and 


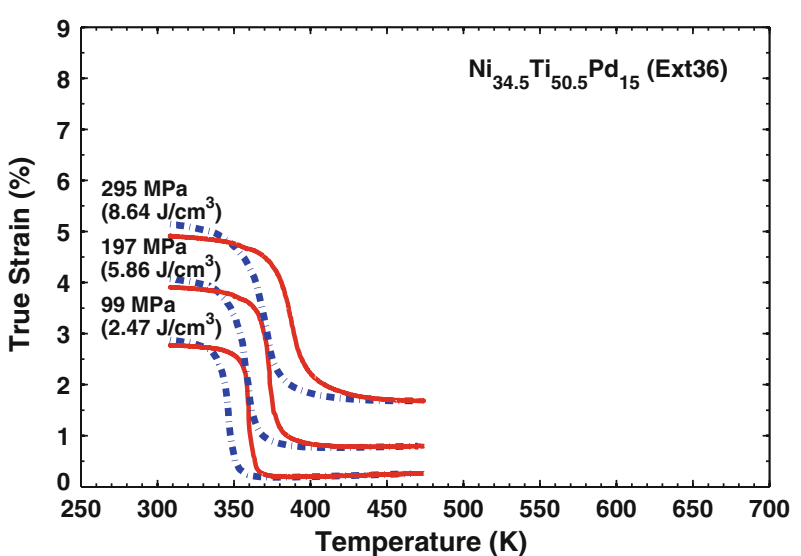

(a)

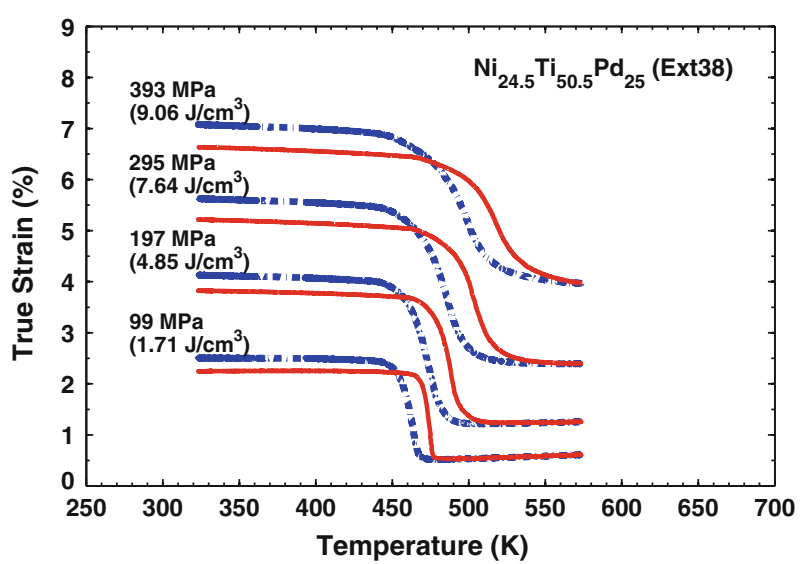

(c)

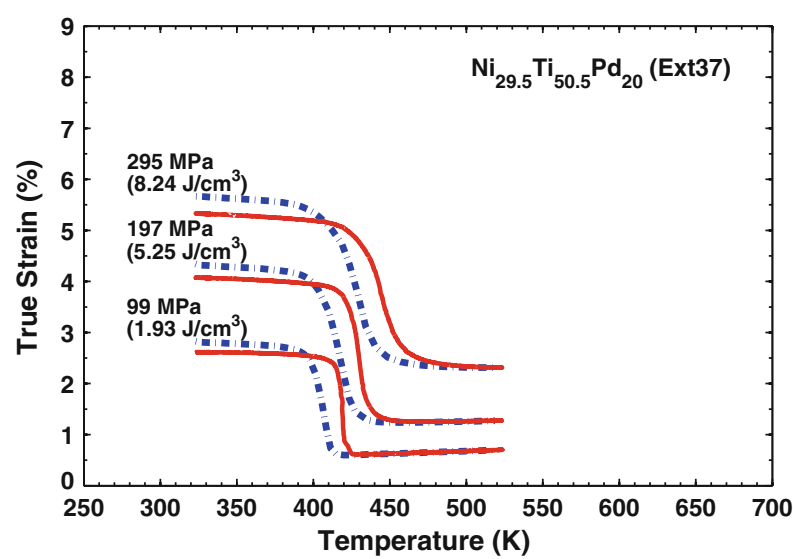

(b)

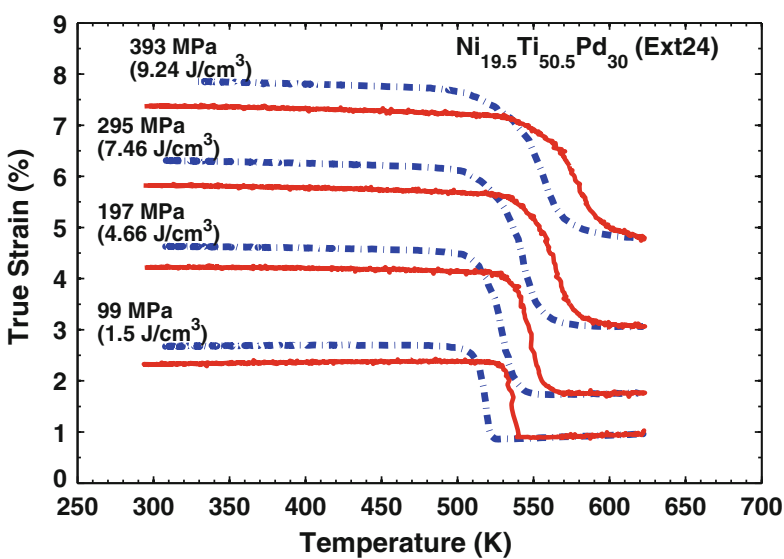

(d)

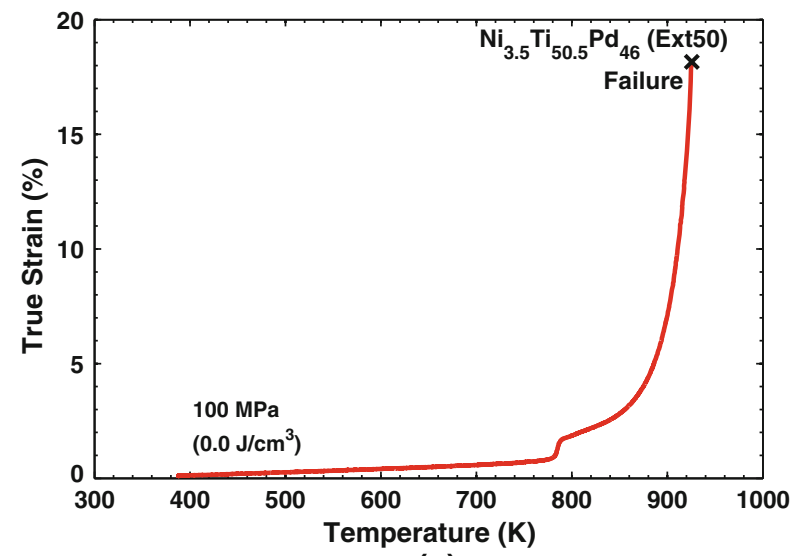

(e)

Fig. 8- (a) through (e) Load-biased strain-temperature curves for the five NiTiPd alloys showing the second cycle response at each stress level. Note the different strain and temperature scales for (e).

the applied stress, increased with applied stress for all of the stress levels reached (Figure 10), but would have eventually reached a maximum if even higher stress levels were attained, as our previous work on $\mathrm{Ni}_{19.5}$ $\mathrm{Ti}_{50.5} \mathrm{Pd}_{30}$ in compression has shown. ${ }^{[13]}$ In this case, the tensile samples failed before this condition was reached.

The amount of open-loop or unrecovered strain that occurred during each cycle (Figure 11) increased with both increasing Pd content and increasing stress level.
However, some unrecovered strain was observed at every stress level tested, indicating that dimensional stability is an issue with all the NiTiPd alloys investigated, regardless of $\mathrm{Pd}$ content and even at relatively low temperatures and stresses such as those used in testing the $\mathrm{Ni}_{34.5} \mathrm{Ti}_{50.5} \mathrm{Pd}_{15}$ alloy. The possible mechanisms responsible for this unrecovered strain is the topic of a follow-up article, but the result itself is consistent with a growing body of work, which suggests that 


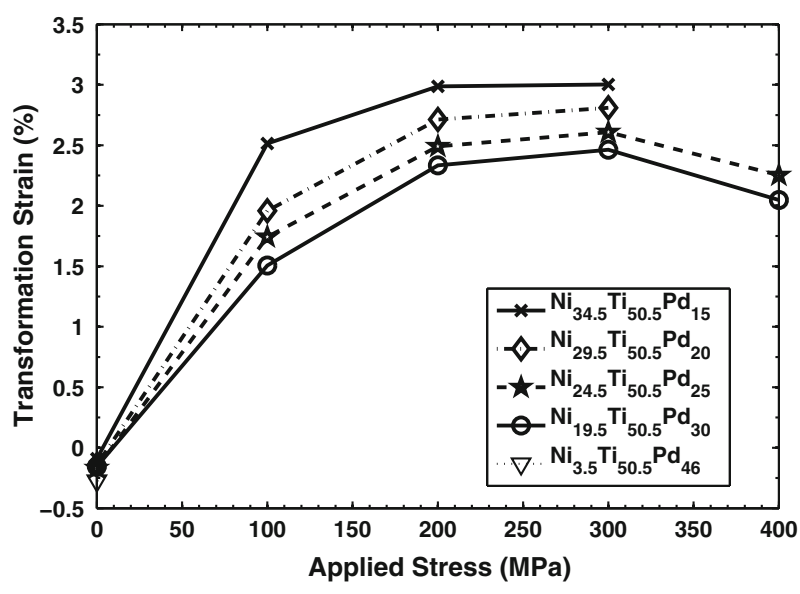

Fig. 9-Recovered transformation strain as a function of applied stress for NiTiPd alloys of varying Pd content.

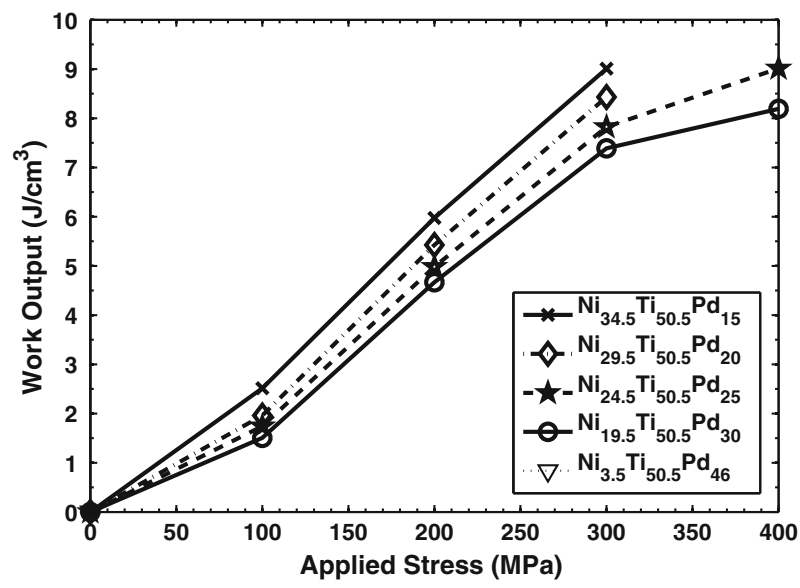

Fig. 10-Work output as a function of applied stress for NiTiPd alloys of varying Pd content.

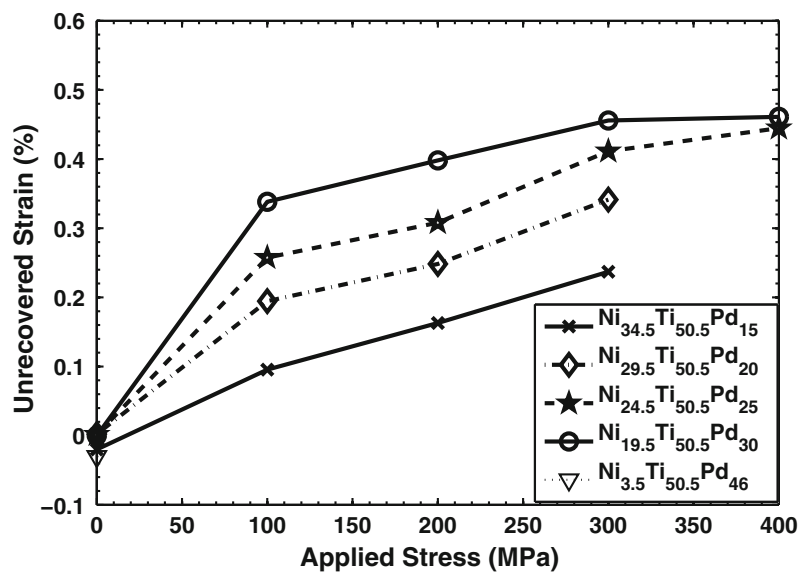

Fig. 11-The amount of unrecovered strain as a function of applied stress during thermal cycling of NiTiPd alloys of varying Pd content.

unrecovered deformation is greater in alloys that tend to be $\mathrm{Ti}$ rich in stoichiometry. In binary $\mathrm{NiTi}$ alloys, Morgan ${ }^{[23]}$ has shown that unrecovered strain is greater

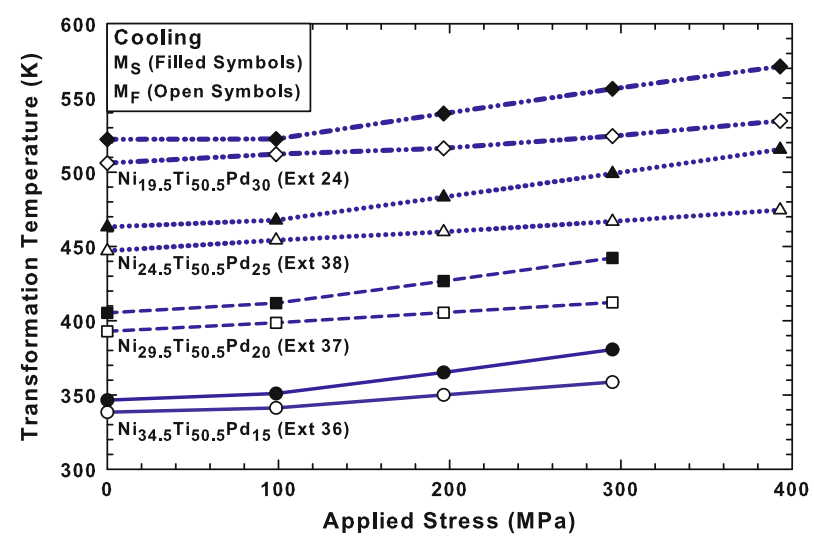

(a)

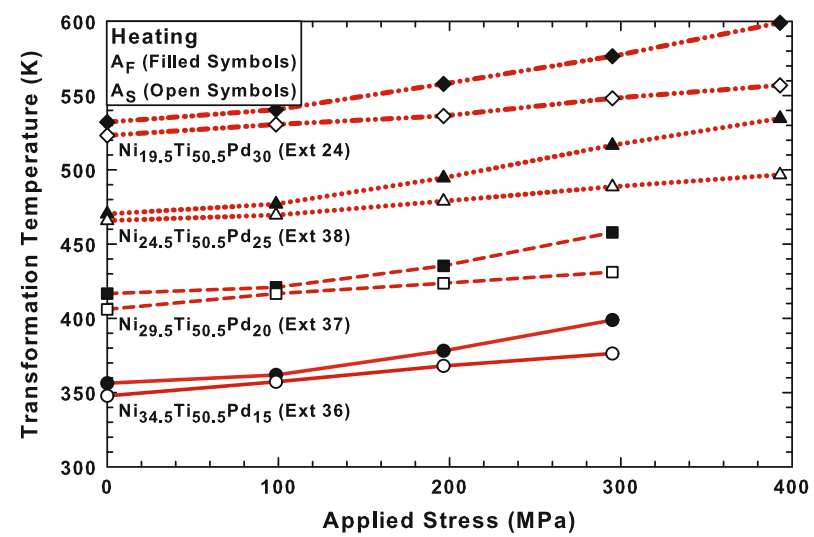

(b)

Fig. 12-Effect of composition and stress on the start and finish of the $(a)$ forward transformation $\left(M_{s}\right.$ and $\left.M_{f}\right)$ and $(b)$ reverse transformation $\left(A_{s}\right.$ and $\left.A_{f}\right)$.

in Ti-rich NiTi alloy wire samples than in Ni-rich compositions. Similar trends have been observed in ternary NiTiPd and quaternary NiTiPdX (where $\mathrm{X}=\mathrm{Au}, \mathrm{Pt}, \mathrm{Hf}$ ) compression samples. ${ }^{[33]}$ Also, Noebe et al. ${ }^{[34,35]}$ have found that NiTiPt alloys exhibit little unrecovered strain over a broad range of stresses for near-stoichiometric and presumably Ni-rich compositions, while the unrecovered strain in tension for Ti-rich compositions, although still very small in an absolute sense, was much greater relative to the near-stoichiometric, Ni-rich compositions.

Compared to the no-load transformation temperatures, all four transformation temperatures increase with increasing applied stress during load-biased testing (Figure 12). The $M_{f}$ and $A_{s}$ temperatures increase linearly for all of the stress levels tested, with an average of $7.0 \mathrm{~K}$ and $9.0 \mathrm{~K} / 100 \mathrm{MPa}$ for the $M_{f}$ and $A_{s}$, respectively. However, the $M_{s}$ and $A_{f}$ temperatures show a disjointed relationship, with the slope between 0 and $100 \mathrm{MPa}$ being much lower than the slope for stresses $100 \mathrm{MPa}$ and higher. For the higher stresses, the slope is 15.6 and $18.4 \mathrm{~K} / 100 \mathrm{MPa}$ for the $M_{s}$ and $A_{f}$, respectively. Thus, higher transformation temperatures are achieved due to the application of stress. However, due to the upper transformation temperatures $\left(A_{f}\right.$ and $M_{s}$ ) increasing more strongly than the $M_{f}$ and $A_{s}$, the 
transformation begins to widen overall, leading to a decrease in possible bandwidth (actuation frequency).

\section{DISCUSSION}

Interest in high-temperature shape-memory alloys has been growing as the potential benefits for adaptive structures and compact actuators have become more evident in the aerospace, automotive, and other industries. However, actual materials development has seriously lagged component design, since current commercial NiTi alloys are severely limited in their temperature capability. As demonstrated in this investigation and generally well known from the literature (i.e., Figure 6), additions of $\mathrm{Pd}$ greater than about 10 at. pct increase the transformation temperature of NiTi alloys, but with few exceptions, ${ }^{[12-14]}$ the shape-memory behavior (strain recovery) of these high-temperature alloys has been determined only under stress-free conditions. Consequently, given the limited amount of basic mechanical test data and general lack of information regarding the work attributes of these materials, the focus of this investigation was on the load-biased shapememory response of ternary NiTiPd alloys as a function of $\mathrm{Pd}$ content. In this article, load-biased shape-memory responses of a series of $\mathrm{Ni}_{49.5-x} \mathrm{Pd}_{x} \mathrm{Ti}_{50.5}(x=15$ to 46 at. pct) HTSMAs that have constant stoichiometry and thus similar microstructure (Figures 2 and 4) but increasing temperature capability, i.e., transformation temperatures (Figure 6), have been studied.

Figure 13 is a plot of recovered transformation strain at various stress levels for the alloys investigated in this study but plotted as a function of transformation temperature, as approximated by the midpoint of the transformation, $1 / 2\left(M_{f}+A_{f}\right)$. The bars through each data point actually represent the full range of the

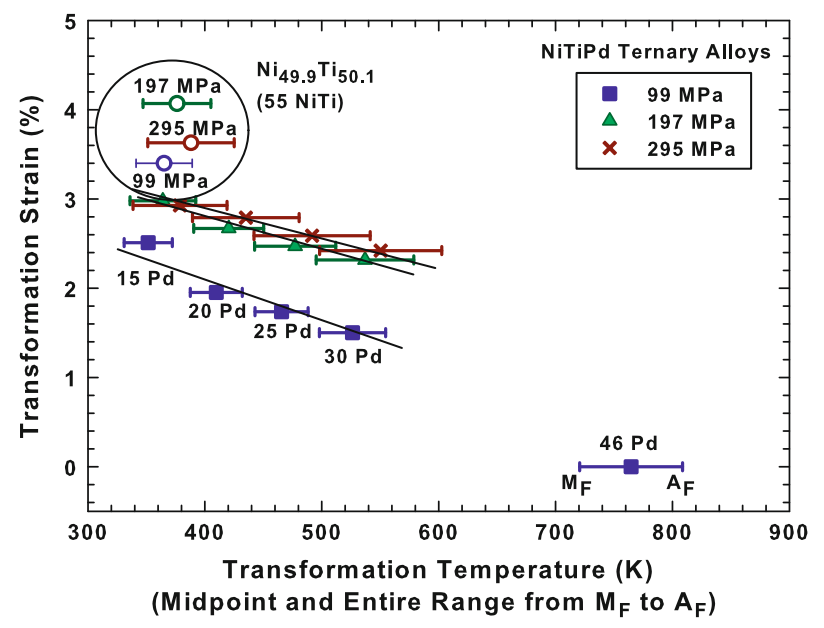

Fig. 13-Relationship between the recovered transformation strain and the load-biased transformation temperature at various constant stresses determined from the test data shown in Fig. 8-The midpoint of the transformation $\left(M_{f}+A_{f}\right) / 2$ is shown and the bars represent the complete range of the transformation from the $M_{f}$ to $A_{f}$ temperature for each alloy investigated. The data are compared to near stoichiometric NiTi, also in the hot-worked condition. ${ }^{[38]}$ transformation from the $M_{f}$ to $A_{f}$ temperature. It is clear from these data that as Pd is added to the system to increase the temperature capability of the alloy, there is a nearly linear decrease in the recovered transformation strain at each stress level. At $99 \mathrm{MPa}$, the recovered transformation strain for alloys containing 15 to 30 at. pct $\mathrm{Pd}$ is between 1.5 to 2.5 pct, well above that of a no-load cycle ( -0.1 to $-0.3 \mathrm{pct})$. This can be attributed to preferential formation of martensite variants of a favorable orientation with respect to the applied stress state, resulting in a large thermoelastic strain in the loading direction, as the sample is cooled through the transformation. ${ }^{[36]}$ This process reduces the internal strain energy of the system, but also provides the basis for a greater recoverable strain during the subsequent heating cycle. Increasing the stress to $197 \mathrm{MPa}$ produces further reorientation of the martensite, resulting in even larger strain capability. Eventually, further increases in stress provide no additional benefit and become detrimental once reorientation saturates (all the martensite plates have reoriented to the extent possible) and other processes begin to contribute to deformation. With increasing stress, alternative, nonrecoverable strain producing mechanisms such as plasticity and the formation of retained martensite begin to increase, impacting the ability of the material to recover strain.

Regardless of the composition (with the exception of the $\mathrm{Ni}_{3.5} \mathrm{Ti}_{50.5} \mathrm{Pd}_{46}$ alloy) or the transformation temperature, the NiTiPd alloys commonly exhibit a peak transformation strain at a stress of about $300 \mathrm{MPa}$, but the actual recoverable strain level at the peak decreases with increasing Pd content (or increasing transformation temperature). One interpretation of this behavior is that reorientation processes saturate at about the same stress level in all alloys but that unrecoverable deformation processes are more active with increasing temperature. In this study, the recovered transformation strain is the amount of contraction measured during the reverse transformation during heating. Therefore, any plastic deformation would cause strain to accumulate in the opposite direction, reducing the amount of recovered strain that is measured. Also, if not all the martensite transforms during the martensite-to-austenite transformation, resulting in retained martensite, then there is less material contributing to the transformation response resulting in a decrease in recovered transformation strain. Previous work indicates that the development of retained martensite with repeated cycling is a significant problem in $\mathrm{Ni}_{29.5} \mathrm{Ti}_{50.5} \mathrm{Pd}_{20} .{ }^{[37]}$

Data for a commercially produced, hot-worked binary $\mathrm{Ni}_{49.9} \mathrm{Ti}_{50.1}$ alloy, commonly referred to as 55NiTi (55 wt pet Ni- 45 wt pct Ti), are also included in Figure 13 for comparison. ${ }^{[38]}$ The binary alloy exhibits a transformation strain at $100 \mathrm{MPa}$ of 3.4 pct, which increases to 4.07 pet at $200 \mathrm{MPa}$, at which point the recoverable transformation strain decreases with additional stress. Although $\mathrm{Ni}_{49.9} \mathrm{Ti}_{50.1}$ and $\mathrm{Ni}_{34.5} \mathrm{Ti}_{50.5} \mathrm{Pd}_{15}$ exhibit comparable transformation temperatures (341 and $338 \mathrm{~K}\left(68{ }^{\circ} \mathrm{C}\right.$ and $\left.65^{\circ} \mathrm{C}\right) M_{f}$ and 356 and $385 \mathrm{~K}(83$ and $\left.112{ }^{\circ} \mathrm{C}\right) A_{f}$, respectively), the maximum recoverable transformation strain in the binary alloy is about $30 \mathrm{pct}$ greater than that of the ternary alloy. This may be an 
inherent difference due to the type of martensite that results with binary NiTi transforming to a low symmetry B19' monoclinic martensite, whereas the NiTiPd alloys studied in this investigation transform to a higher symmetry B19 orthorhombic martensite. However, it should be recognized that this is essentially the upper temperature limit for binary NiTi alloys, and applications requiring actuation at temperatures greater than about $353 \mathrm{~K}\left(80^{\circ} \mathrm{C}\right)$ will require the use of some type of ternary alloy. Consequently, higher temperature capability is achieved at the expense of recovered transformation strain, at least in the case of the NiTiPd alloys studied here.

Work output, being the product of the transformation strain and the applied stress, also decreases with increasing transformation temperature (i.e., higher $\mathrm{Pd}$ content) (Figure 14). Thus, for thermal cycles at $99 \mathrm{MPa}$, work output decreases from $5.86 \mathrm{~J} / \mathrm{cm}^{3}$ in $\mathrm{Ni}_{34.5} \mathrm{Ti}_{50.5} \mathrm{Pd}_{15}$ to $4.55 \mathrm{~J} / \mathrm{cm}^{3}$ in $\mathrm{Ni}_{19.5} \mathrm{Ti}_{50.5} \mathrm{Pd}_{30}$. At high stress levels, where the transformation strains are relatively equivalent (such as 197 and $295 \mathrm{MPa}$ ), an increase in work output was still observed. This increase occurs because work is a mathematical product of stress and transformation strain; hence, an increase will be observed for higher stresses even when the transformation strain is unchanged. However, if high enough stresses could be reached in tension, work output would eventually drop since transformation strains often decrease at higher levels of stress.

The work capability of the $\mathrm{Ni}_{34.5} \mathrm{Ti}_{50.5} \mathrm{Pd}_{15}$ was about 70 pct of that exhibited by the binary $\mathrm{Ni}_{49.9} \mathrm{Ti}_{50.1}$ material at a given stress level (Figure 14). Both of these materials were hot worked and consisted of an equiaxed and recrystallized grain structure (NiTiPd: 10 to $15 \mu \mathrm{m}$, 55NiTi: 15 to $20 \mu \mathrm{m}$ ), providing a fair basis for comparison in work capabilities. The difference in transformation strain, and therefore work output, is partially due to the difference in the recoverable

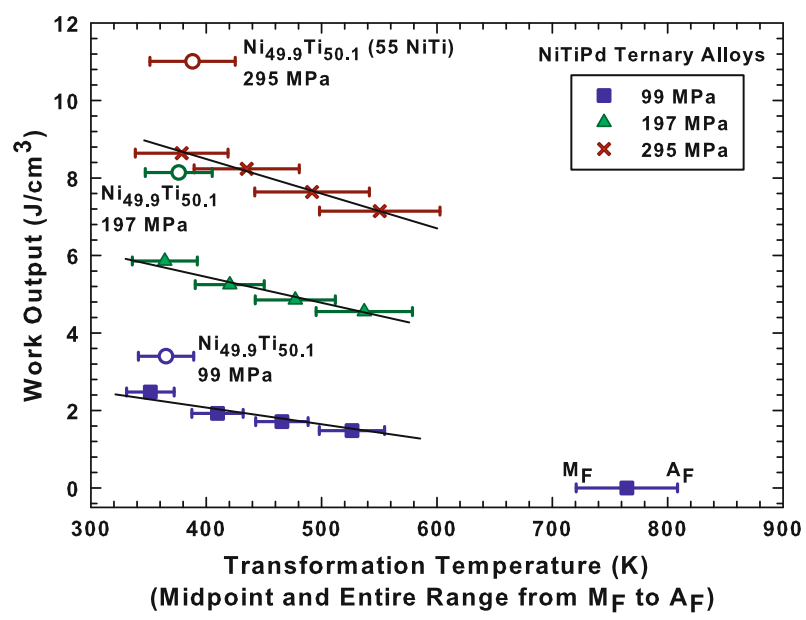

Fig. 14-Relationship between work output and the load-biased transformation temperature at various constant stresses determined from the test data shown in Fig. 8. The bars across each data point represent the complete range of the transformation from the $M_{f}$ to $A_{f}$ temperature for each alloy investigated. The data are compared to near stoichiometric NiTi, also in the hot-worked condition. ${ }^{[38]}$ transformation strain inherently tied to the crystallography of transformation in each alloy. Binary NiTi transforms from B2 to monoclinic B19' martensite, achieving higher strains as compared to the NiTiPd alloys in this study, which transform from B2 to an orthorhombic B19 martensite (higher symmetry than monoclinic). Furthermore, it has been shown in the literature that, through specialized thermomechanical processing, cold work and anneal treatments, and "training" (repetitive thermomechanical cycling to improve dimensional stability and to stabilize transformation strain and temperature), it is possible to get a maximum work output as high as $25 \mathrm{~J} / \mathrm{cm}^{3}$ from binary NiTi alloys, ${ }^{[39,40]}$ compared to $11.0 \mathrm{~J} / \mathrm{cm}^{3}$ for the hotworked $\mathrm{Ni}_{49.9} \mathrm{Ti}_{50.1}$ used for comparison in this study. The hot-worked $\mathrm{Ni}_{49.9} \mathrm{Ti}_{50.1}$ alloy was intentionally chosen as the baseline material for comparison because of the similarity in processing and microstructure with the ternary materials. Consequently, since binary alloy properties can be improved considerably through additional thermomechanical processing, it is hoped that similar levels of improvement in work output may be achieved by optimizing the processing of the NiTiPd alloys as well.

In all of the alloys, some amount of unrecovered strain occurred at every stress level used during the loadbiased thermal cycling tests (Figure 15). For ternary NiTiPd, the amount of unrecovered strain increases in an approximately linear fashion with increasing transformation temperature (and $\mathrm{Pd}$ content) between 15 and 30 at. pct $\mathrm{Pd}$. However, the amount of unrecovered strain at a given stress level during thermal cycling was even more prominent in the binary NiTi alloy. In fact, the ternary alloys exhibited just a small fraction of the unrecovered strain observed in the $\mathrm{Ni}_{49.9} \mathrm{Ti}_{50.1}$ (Figure 15). For example, the permanent deformation from a single thermal cycle at $295 \mathrm{MPa}$ (constant stress) is 0.23 pct in $\mathrm{Ni}_{34.5} \mathrm{Ti}_{50.5} \mathrm{Pd}_{15}$, increases to 0.48 pct in

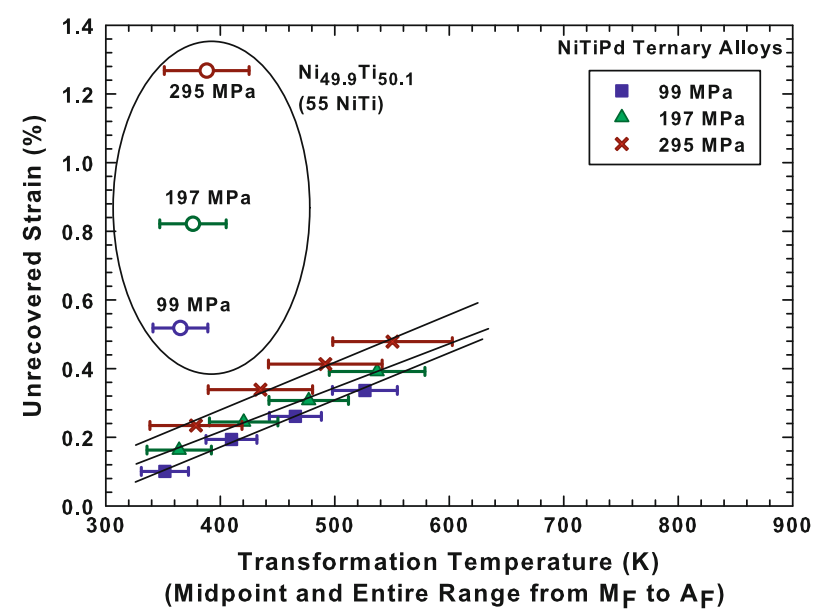

Fig. 15-Relationship between the unrecovered strain and the loadbiased transformation temperature at various constant stresses determined from the test data shown in Fig. 8. The bars across each data point represent the complete range of the transformation from the $M_{f}$ to $A_{f}$ temperature for each alloy investigated. The data are compared to near stoichiometric $\mathrm{NiTi}$, also in the hot-worked condition. ${ }^{[38]}$ 
$\mathrm{Ni}_{19.5} \mathrm{Ti}_{50.5} \mathrm{Pd}_{30}$, and is 1.27 pct in $\mathrm{Ni}_{49.9} \mathrm{Ti}_{50.1}$. Therefore, even though the binary alloy has a lower application temperature and saw lower temperatures during thermal cycling (maximum upper cycle temperature of $230{ }^{\circ} \mathrm{C}$ ) than all but the $\mathrm{Ni}_{34.5} \mathrm{Ti}_{50.5} \mathrm{Pd}_{15}$, it is less stable dimensionally than all of the ternary NiTiPd alloys. This is inherent material behavior, because both the binary and ternary systems have been studied in the hotworked and untrained condition. There could be several reasons for this difference. First, Pd could be acting as a solid-solution strengthening agent, which helps the high-temperature austenite phase and even the martensite phase resist plastic deformation and other possible inelastic deformation processes. Second, the martensite and austenite phases for the NiTiPd alloys exhibit greater compatibility than in binary NiTi alloys, according to criteria established by Zhang et al., ${ }^{[27]}$ and so the shear transformation and volume change would be expected to proceed with much less need for accommodation by plastic deformation/microstructural evolution.

This large unrecovered strain per cycle, even for the NiTiPd alloys, would be problematic for any application requiring repeated cycling if it were to continue at this level, as dimensional instability is undesirable. Loss of tolerance as the SMA element elongates during use will cause the actuator to no longer function properly or will result in early failure of the SMA by low-cycle fatigue. Consequently, the issue is whether the unrecovered strain measured during the second thermal cycle under stress is actually representative of the material behavior during repeated thermal cycling under load.

Consequently, repeated thermal cycling was performed on the $\mathrm{Ni}_{19.5} \mathrm{Ti}_{50.5} \mathrm{Pd}_{30}$ and $\mathrm{Ni}_{24.5} \mathrm{Ti}_{50.5} \mathrm{Pd}_{25}$ alloys as they exhibited the largest amount of unrecovered strain per cycle of the ternary alloys studied. This information was then compared to the cyclic behavior of the $\mathrm{Ni}_{49.9} \mathrm{Ti}_{50.1}$ (Figure 16). The response of the ternary and binary alloys to repeated cycling is rather interesting as they display differing behaviors. For the ternary alloy, the per-cycle change in unrecovered strain is relatively large during the first few cycles, but decreases rapidly, even for the high stress case (345 MPa) (Figure 16(a)). In the case of the $172 \mathrm{MPa}$ stress, it saturates to $0.0087 \mathrm{pct}$ strain/cycle (average for cycles 40 to 100). In other words, the material is self-training with

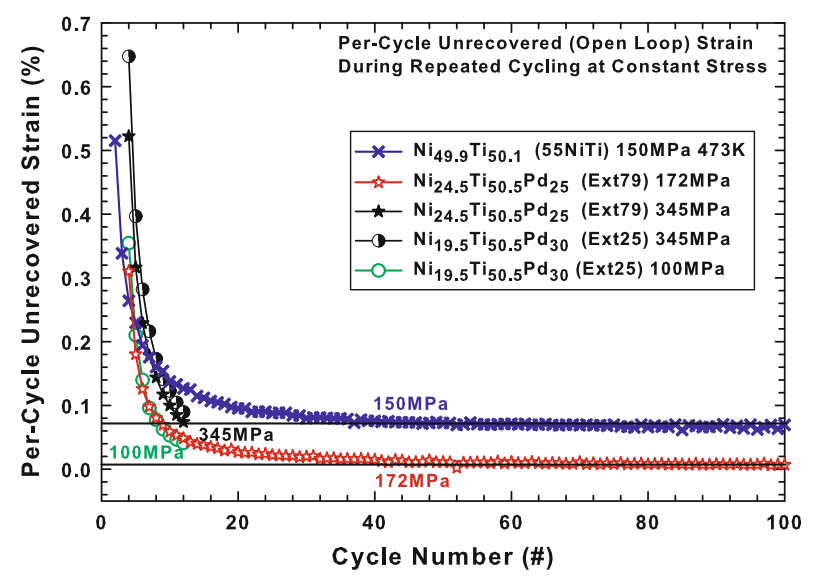

(a)

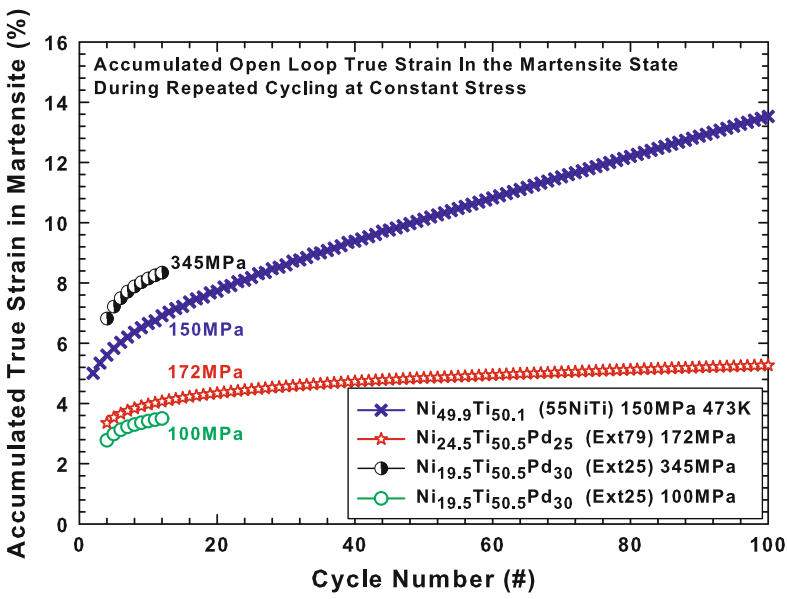

(b)

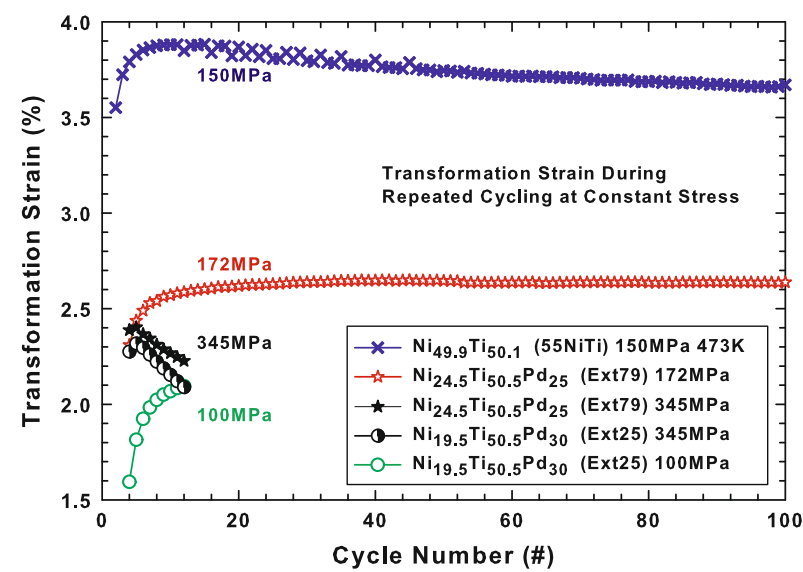

(c)

Fig. 16 - (a) Per-cycle unrecovered (open loop) strain for $\mathrm{Ni}_{19.5} \mathrm{Ti}_{50.5} \mathrm{Pd}_{30}$ and $\mathrm{Ni}_{24.5} \mathrm{Ti}_{50.5} \mathrm{Pd}_{25}$ repeatedly cycled at 100,172 , and $345 \mathrm{MPa}$ and for binary NiTi cycled at $150 \mathrm{MPa}^{[38]}(b)$ The total amount of unrecovered (open loop) strain accumulated during cycling. (c) Transformation strain (recovered strain) per cycle for the same conditions as in (a) and (b). 
cycling achieving almost dimensionally stable behavior. This suggests that the microstructural evolution that occurs in the first few cycles is stabilized with cycling, allowing the martensitic transformation to proceed thermoelastically without significant further plastic deformation or evolution of the martensitic variants. In contrast, the amount of unrecovered strain per cycle for the binary alloy also decreases initially but it does not saturate to near zero, even though it is at a lower stress than the ternary alloy (150 MPa compared to $172 \mathrm{MPa}$ ), but instead converges to a finite average strain of $0.069 \mathrm{pct} / \mathrm{cycle}$ (cycles 40 to 100), almost eight times the amount seen in the ternary alloy. Thus, the sample continues to elongate almost linearly with cycle count, as shown by the accumulation of strain in the martensite shown in Figure 16(b). In the case of the binary alloy, it is apparent that the martensitic transformation does not proceed in a completely thermoelastic manner but apparently requires about 0.069 pet strain to accommodate the transformation with each cycle. Note that although a comparison has been made at $\sim 150 \mathrm{MPa}$ here, it should be recognized that the stress-temperature stability space may be different for the ternary and binary alloys.

The same trend is observed in the transformation strain, as shown in Figure 16(c). The cycle-to-cycle change between the first few cycles is large, decreases, and eventually converges to a constant rate. For example, in the $\mathrm{Ni}_{24.5} \mathrm{Ti}_{50.5} \mathrm{Pd}_{25}$ alloy at $172 \mathrm{MPa}$, the transformation strain actually increases initially with cycle count and then saturates to a near constant value of 2.64 pct in $\sim 40$ cycles with less than $-1 \times 10^{-4}$ pct/ cycle change thereafter. It should be noted that the transformation strain saturates at the same number of cycles $(\sim 40)$ as the unrecovered strain. For the high stress state $(345 \mathrm{MPa})$ in the $\mathrm{Ni}_{19.5} \mathrm{Ti}_{50.5} \mathrm{Pd}_{30}$, there is an increase in transformation strain only in the first cycle and then a decrease in strain for the remaining cycles. The transformation strain for the binary NiTi alloy displays similar behavior at $150 \mathrm{MPa}$ (Figure 16(c), showing a large initial increase, peaking within the first 20 cycles, and then a slow decrease in transformation strain $\left(-1.84 \times 10^{-3} \mathrm{pct} / \mathrm{cycle}\right)$ with no stabilization even up to 100 cycles. Thus, it can be seen that, at $\sim 150 \mathrm{MPa}$, stabilization can be accomplished much more easily in the ternary alloy as compared to the binary alloy.

\section{SUMMARY AND CONCLUSIONS}

Constant-load thermal cycles were performed on Ti-rich, ternary $\mathrm{Ni}_{49.5-x} \mathrm{Ti}_{50.5} \mathrm{Pd}_{x}(x=15,20,25,30$, and 46 at. pct) alloys of similar microstructure to determine the shape-memory behavior under load and to assess the suitability of these alloys for actuator applications. Over the composition range studied, there was a linear increase in transformation temperature with $\mathrm{Pd}$ content from an $A_{f}$ of $356 \mathrm{~K}\left(83^{\circ} \mathrm{C}\right)$ in $\mathrm{Ni}_{34.5} \mathrm{Ti}_{50.5} \mathrm{Pd}_{15}$ to $786 \mathrm{~K}\left(51{ }^{\circ} \mathrm{C}\right)$ in $\mathrm{Ni}_{3.5} \mathrm{Ti}_{50.5} \mathrm{Pd}_{46}$. With the increase in $\mathrm{Pd}$ content, and therefore transformation temperature, the alloys exhibited a modest decrease in available work output and also an increase in unrecovered strain. Despite this, the work outputs achievable in these alloys were more than half that of similarly processed binary NiTi, while the unrecovered strain during continued cycling was superior to that of the binary NiTi even for alloys with significantly higher transformation temperatures. Furthermore, these alloys could be self-trained, resulting in a slight increase in transformation strain and, more importantly, nearly complete elimination of any unrecovered strain after repeated thermal cycling under stress.

\section{ACKNOWLEDGMENT}

This work was supported by NASA's Fundamental Aeronautics Program, Subsonic Fixed Wing Project.

\section{REFERENCES}

1. R.D. Noebe, T. Biles, and S.A Padula, II: Advanced Structural Materials: Properties, Design Optimization, and Applications, Taylor \& Francis CRC Press, Boca Raton, FL, 2007, pp. 145-86.

2. A. Stebner, S.A. Padula, II, R.D. Noebe, and D.D. Quinn: Proc. SPIE, 2008, vol. 6928, pp. 69280X.1-69280X.12.

3. N.G. Boriskina and E.M. Kenina: Proc. 4th Int. Conf. on Titanium, TMS-AIME, Warrendale, PA, 1980, pp. 2917-27.

4. H.C. Donkersloot and J.H. Van Vucht: J. Less-Common Met., 1970, vol. 20, pp. 83-91.

5. P.G. Lindquist and C.M. Wayman: Engineering Aspects of Shape Memory Alloys, Butterworth-Heinemann, Ltd., Boston, MA, 1990, pp. 58-68.

6. S. Shimizu, Y. Xu, E. Okunishi, S. Tanaka, K. Otsuka, and K. Mitose: Mater. Lett., 1998, vol. 34, pp. 23-29.

7. V.N. Kachin, N.A. Matveeva, V.P. Sivokha, and D.V. Chernov: Dokl. Akad. Nauk SSSR, 1981, vol. 257, pp. 167-69.

8. K. Otsuka, K. Oda, Y. Ueno, M. Piao, T. Ueki, and H. Horikawa: Scripta Metall. Mater., 1993, vol. 29, pp. 1355-58.

9. W.S. Yang and D.E. Mikkola: Scripta Metall. Mater., 1993, vol. 28, pp. 161-65.

10. D. Goldberg, Y. Xu, Y. Murakami, S. Morito, K. Otsuka, T. Ueki, and H. Horikawa: Scripta Metall. Mater., 1994, vol. 30, pp. 1349-54.

11. Q. Tian, J. Wu, and C. Xie: Proc. SPIE, 2001, vol. 4333, pp. $452-$ 59.

12. W. Cai, S. Tanaka, and K. Otsuka: Mater. Sci. Forum, 2000, vols. 327-328, pp. 279-82.

13. R. Noebe, S. Padula, II, G. Bigelow, O. Rios, A. Garg, and B. Lerch: Proc. SPIE, 2006, vol. 6170, pp. 617010.1-617010.13.

14. P.K. Kumar, D.C. Lagoudas, K.J. Zanca, and M.Z. Lagoudas: Proc. SPIE, 2006, vol. 6170, pp. 306-12.

15. C.M. Wayman and H.R.P. Inoue: Intermetallic Compounds, John Wiley and Sons, New York, NY, 1995, pp. 827-47.

16. N.M. Matveeva, W.N. Khachin, and W.P. Sivokha: Stable and Metastable Phase Equilibrium in Metallic Systems, Nauka, Moscow, 1985, p. 25.

17. G.F. Bastin and G.D. Rieck: Metall. Trans., 1974, vol. 5, pp. 1817-26.

18. M.V. Nevitt: Trans. TMS-AIME, 1960, vol. 218, pp. 327-31.

19. M. Nishida, C.M. Wayman, and T. Honma: Metall. Trans. A, 1986, vol. 17A, pp. 1505-15.

20. T.W. Duerig and A.R. Pelton: Materials Properties Handbook: Titanium Alloys, ASM INTERNATIONAL, Materials Park, OH, 1994, pp. 1035-48.

21. W. Cai and K. Otsuka: Scripta Mater., 1999, vol. 41, pp. 1311-17.

22. Y. Xu, S. Shimizu, Y. Suzuki, K. Otsuka, T. Ueki, and K. Mitose: Acta Mater., 1997, vol. 45, pp. 1503-11.

23. N. Morgan: Eng.D. Dissertation, Cranfield University, Oxfordshire, United Kingdom, 1999.

24. J.E. Hanlon, S.R. Butler, and R.J. Wasilewski: Trans. AIME, 1967, vol. 239, pp. 1323-26. 
25. K. Otsuka and X. Ren: Prog. Mater. Sci., 2005, vol. 50, pp. 511-678.

26. Z. Zhang: Ph.D. Dissertation, University of Minnesota, Minneapolis, MN, 2007.

27. Z. Zhang, R.D. James, and S. Muller: Acta Mater., 2009, vol. 57, pp. 4332-52.

28. Z.G. Wei, R. Sandström, and S. Miyazaki: J. Mater. Sci., 1998, vol. 33, pp. 3743-62.

29. S.A. Padula, II, D.J. Gaydosh, R.D. Noebe, G.S. Bigelow, A. Garg, D. Lagoudas, I. Karaman, and K.C. Atli: Proc. SPIE, 2008, vol. 6929, pp. 692912.1-692912.11.

30. S. Miyazaki, T. Imai, Y. Igo, and K. Otsuka: Metall. Trans. A, 1986, vol. 17A, pp. 115-20.

31. T.J. Lim and D.L. McDowell: Proc. SPIE, 1994, vol. 2189 , pp. $153-65$

32. D.A. Miller and D.C. Lagoudas: Mater. Sci. Eng. A, 2001, vol. 308 , pp. $161-75$.
33. G.S. Bigelow, D.J. Gaydosh, A. Garg, S.A. Padula II, and R.D. Noebe: Proc. SMST, 2007, pp. 83-92.

34. R. Noebe, D. Gaydosh, S. Padula, II, A. Garg, T. Biles, and M. Nathal: Proc. SPIE, 2005, vol. 5761, pp. 364-75.

35. R. Noebe, S. Draper, D. Gaydosh, A. Garg, B. Lerch, N. Penney, G. Bigelow, S. Padula II, and J. Brown: Proc. SMST, 2006, pp. 409-26.

36. K. Gall, J. Tyber, V. Brice, C.P. Frick, H.J. Maier, and N. Morgan: J. Biomed. Mater. Res. A, 2005, vol. 75A, pp. 810-23.

37. S. Qiu: PhD Dissertation, University of Central Florida, Orlando, FL, 2010.

38. NASA Glenn Research Center, Cleveland, $\mathrm{OH}$, unpublished research, 2009.

39. K.D. Skrobanek, M. Kohl, and S. Miyazaki: Proc. of SPIE, 1996, vol. 2779 , pp. 499-504.

40. P. Krulevitch, A.P. Lee, P.B. Ramsey, J.C. Trevino, J. Hamilton, and M.A. Northrup: J. Microelectromech. Sys., 1996, vol. 5, pp. 270-282. 